Portland State University

PDXScholar

1979

\title{
An evaluative study of the Good Samaritan Pain Evaluation Clinic
}

Frederic G. Wessinger Jr.

Portland State University

Follow this and additional works at: https://pdxscholar.library.pdx.edu/open_access_etds

Part of the Counseling Commons, and the Social Work Commons Let us know how access to this document benefits you.

Recommended Citation

Wessinger, Frederic G. Jr., "An evaluative study of the Good Samaritan Pain Evaluation Clinic" (1979). Dissertations and Theses. Paper 2802.

https://doi.org/10.15760/etd.2798

This Thesis is brought to you for free and open access. It has been accepted for inclusion in Dissertations and Theses by an authorized administrator of PDXScholar. Please contact us if we can make this document more accessible: pdxscholar@pdx.edu. 
AN EVALUATIVE STUDY OF THE GOOD SAMARITAN

PAIN EVALUATION CLINIC

by

FREDERIC G. WESSINGER, JR.

A practicum submitted in partial fulfillment of the requirements for the degree of

MASTER OF SOCIAL WORK

Portland State Univeristy

1979 
TO THE OFFICE OF GRADUATE STUDIES AND RESEARCH:

The following advisors approve the practicum of

Frederic G. Wessinger, Jr. presented June 1, 1979.

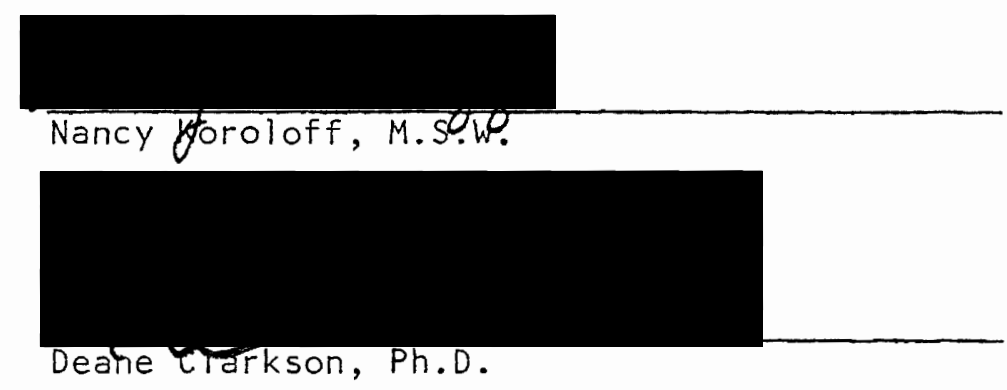


TABLE OF CONTENTS

PAGE

CHAPTER

I INTRODUCTION .......................

II OVERVIEW OF THE CLINICS FUNCTION........ 1

III LITERATURE SURVEY .................. 4

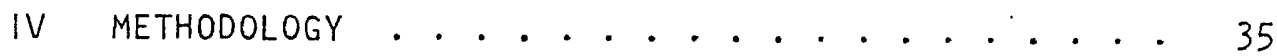

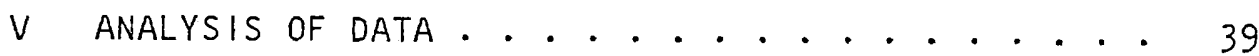

V! RESULTS ....................... 40

VII INTERPRETATION OF RESULTS .......... 47

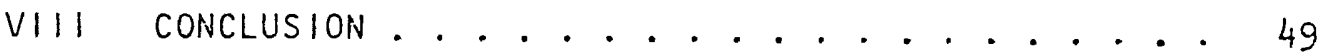

IX BIBL IOGRAPHY................. 50

X BASIC DATA DESCRIPTION............... 53 


\section{INTRODUCTION}

Purpose. The purpose of this study is to ascertain whether or not the Good Samaritan Pain Evaluation Clinic can be considered a success.

Program's Function. The Good Samaritan Pain Evaluation Clinic is an outpatient. program which treats patients who have been in pain for six months or more. The kind of pain it treats is psychogenic. That is, persistent pain which is better understood in psychological rather than in physical language and includes pain that has a physiological cause but no medical method to alleviate it. With the usage of a combination of modalities; transcutaneous stimulation, counseling, behavior therapy, physical therapy, and occasionally biofeedback and hypnosis, the clinic aims to help the patient reduce medication and function effectively in his environment despite his pain, and in many cases, hopefully alleviate his pain altogether.

The clinic's staff consists of a registered nurse who examines each patient upon admission, three counselors, (one M.A. psychologist, one social worker, and a psychologist who is the program director), and a physical therapist.

Rationale. This researcher aims to find out if patients who have completed the program can currently be considered to have reached success or failure as a result of the program. Criteria for success is one or more of the following: Reduction of medications, reduction of perceived pain, and improvement in psychological functioning. It is also hoped that this study will be published in order to give all pain clinics, who use the same or similar approach, in the United States an indication 
of how effective their programs are.

Assumption. It is assumed that a representative selection of patients will be willing to participate in the follow-up study.

Limitations. A limitation is the possibility of a low response rate. Also the follow-up will only involve those who are willing to respond. This may omit those patients who did not have success in the program and consequently refused to participate. Secondly, many patients had to be contacted by mail rather than seeing them in person. Only those who were willing to come in were seen in person. 


\section{OVERVIEW OF THE CLINIC'S FUNCTION}

The Good Samaritan Pain Evaluation Clinic is a program which operates on a philosophy developed by Wilbert Fordyce. Fordyce is a psychologist at the University of Washington who believes that pain without physiological explanation is operantly learned. That is, the patient has learned a response to pain which brings about rewarding consequences causing the response to pain to increase or at least be maintained. The pain usually originates from a physical cause but despite medical treatment, the pain fails to decrease.

Fordyce believes that the goal of the pain clinic is to help the individual look at what it is in the environment which is reinforcing the patient's pain and see what can be done about removing those reinforcers. Good Samaritan accomplishes this in the following ways:

1. They treat only those patients who have a doctor's referral.

2. The patient must have a chronic pain condition. 1.e.: Pain that has lasted six months or more.

3. No related mal ignant disease.

4. Acceptance by the patient of the program.

The first part of the program is called "Phase 1." In Phase I a counselor meets with the patient to obtain an idea of the patient's current life style and the extent of his pain. Tools which help to obtain this information are the Minnesota Multiphasic Personality Inventory (M.M.P.I.), the daily log sheets, The McGill Pain Assessment Questionnaire, and the Sacks Sentence Completion Test.

The M.M.P.I. basically points out neurotic tendencies the patient may have and gives the counselor a fairly good understanding of anxieties 
and fears the patient may have, whether or not there is a severe disorganization of thought processes, how probable addiction or habituation to medication is, how likely increases in activity are likely to be reinforcing to the patient. It also shows defenses which help to avoid threatening stimuli, how suitable the individual is for treatment, and how the individual might react when under stress.

The Sack's Sentence Completion Test and The Rotter give the counselor a broader understanding of the above and help him to determine whether the patient's pain is due to a combination of psychological and physical reasons, whether it's primarily due to psychological reasons, or whether it's purely physical. In any case, the counselor accepts the fact that the pain is real and not imaginary. The counselor also realizes that his goal is to help the patient function with his pain and realize what he's getting out of his pain, e.g., avoiding work. It is hoped that the pain will be alleviated as a result.

The MCGill Pain Assessment Questionnaire gives the counselor a broader understanding of how much and to what extent the patient is expèriencing pain.

Next, the patient is evaluated by the physical therapist to see what he can and cannot do. The physical therapist then assigns the patient exercises to work on. (Occasionally he instructs them to use a transcutaneous stimulator, an electronic device, which when placed on the pain area scrambles the pain message to the brain, thereby reducing the pain!

Through further counseling, the counselor establishes psychosocial goals for the patient to work on. Both the physical and psychosocial 
goals are broken into smaller tasks the patient is to reach. The patient is then given some sheets called daily logs. The patient is instructed to fill out the daily logs and bring them in the following week to discuss the patient's progress. Depending on how defensive the patient is will determine whether or not the counselor will show the patient what his pain serves for him directly or indirectly. The patient is also instructed to bring in his spouse at the next meeting. The counselor assesses how willing the spouse is to help the patient overcome his pain behaviors so that he can function effectively. The counselor determines what the spouse is doing to reinforce the pain behaviors.

After this meeting, the staff meets to decide whether or not the patient will benefit from the program, how willing he and the spouse are to participate are evaluated, and it is decided if he needs further medical evaluation and/or treatment. It is also decided, for example, if the patient should be referred elsewhere for biofeedback or hypnosis. It is also decided if it would be helpful for the spouse to become involved in a spouse group to receive counseling and support around what it's like to live with a pain patient and to learn some ways to help the patient function. If the patient is accepted, he will receive further counseling and physical therapy. The average length of time is three months.

The Literature Survey to follow focuses on studies of the emotional aspects of pain patients. Studies which evaluate treatment modalities used by the Good Samaritan Pain Evaluation Clinic, and evaluative studies carried out in pain clinics are discussed. 


\section{LITERATURE SURVEY}

Some theorists speculate that pain behaviors originate in childhood. Psychological tests of chronic pain patients report more experiences associated with pain experiences and with conflicts in childhood than non-pain patients. In 1973, Sternbach found more indication of pervasive depression with many chronic pain patients.

Wilbert Fordyce stated: "It is reasonable to expect, and is confirmed by studies, that the child who receives a lot of punishment may experience anger or hostility toward the source of his distress. The anger cannot be expressed directly since it would bring about further punishment and pain. Clinically, withheld anger is observed of ten to lead to depressive and guilt feelings or to muscle tensions and headaches." (Fordyce, 1976) The finding of hostile feelings as another characteristic was reported in a study conducted by Merskey and Spear in 1967. Merskey and Spear found too, that pain patients differed from pain controls who reported no pain in several ways: 1. They were more neurotic. 2. They had poorer marital and sexual adjustments. 3. They tended to have more hostile feelings. They found too, that a pain sufferer would often identify a phenomenon to be pain when it was some other form of emotional distress.

In 1971, Bond studied women who had cervical cancer. Both those who did and did not report pain had elevated hypochondrial scores, although patients with pain had higher scores than those who were pain free. Such studies stated Fordyce, show that when there is chronic pain there is likely to be an increase in depression or psychic distress, hypochondria, hysteria, and other neurotic scores. (Fordyce, 1976) 
The following studies reinforce Fordyce's thesis that there is depression and neurotic tendencies in the individual who is experiencing chronic pain.

Pilowsky, Chapman and Bonica administered the Illness Behavior Questionnaire and the Levine Pilowsky Depression Questionnaire (LPN) to 100 chronic pain patients to look at the relationship between depression, illness behavior, and persistent pain. The pain patients showed greater conviction of disease and somatic preoccupation than the comparison group. (Pain, 1976)

Ferrer-Brechner, V. L. Brechner and C. P. McCreary gave fifty-one chronic pain patients the M.M.P.I. and the Eysenack Personality Inventory, the Internal-External Locus of Control Scale, Questionnaire A, an inventory designed to measure assertiveness. Generally, the pain patient population showed deviations of hypochondriasis, depression, and hysteria indicating the pain patients have a large emotional component in their pain disorders. (Bonica, 1976)

Merskey states: "It is generally recognized that pain can be caused by psychiatric illness, especially anxiety and depression. If pain is not caused by psychological illness, it may nevertheless be made worse by it. Depressive illnesses, anxiety illnesses, and hysterical personalities provide the main group of psychiatric patients who suffer from chronic pain." (Merskey, 1977).

Merskey continues to state: "In pain clinics, it is rare to meet anyone amongst the patients whose emotional state is really normal. Most workers in the field, dealing with patients with painful organic lesions observe that there is much emotional disturbance, mainly showing 
itself as anxiety and depression. But resentment and demanding attitudes are all well recognized, the former particularly if the pain has not been relieved despite initial efforts." (Merskey, 1977).

Sternbach states: "Those people with psychogenic pain tend to be neurotic." (Sternbach, 1976). He states the following reason: "Pain is associated in our minds for carelessness or wrong doing when we were children and as adults the experience of pain causes us to seek to find something we did to bring on the pain...the patient experiences both a certain amount of confusion as to the meaning of his suffering and a bitterness that others who are more wicked or sinful seem to be enjoying their lives without pain." (Sternbach, 1976).

Engel states: "Almost always these patients have excessive guilt feelings, conscious or unconscious, and the experience of pain serves as punishment which serves to relieve this guilt feeling. Such. patients repeatedly get themselves into situations or relationships in which they are hurt and defeated, and this is when their health is best. Conversely, when their life situation improves they suffer again (or more) from pain. They are thus intolerant of success. These patients are usually reared in a family situation in which aggression and pain figured prominently. Either the patients experienced frequent abuse, thus learning that painful attention meant that the parents cared or else distant parents showed concern only when the patients were sick or hurt. In any case, a pattern of suffering was usually established in childhood. (Sternbach, 1976).

In adolescence and adulthood, specific incidents typically initiate or exacerbate pain states. There may be some form of success which 
threatens the role of the suffering person, a real or threatened loss, or the arousal of strong and forbidden feelings (usually sexual or aggressive ones) that must be controlled. The experience of pain serves to punish the individual for his unacceptable hostile, sexual, or dependent impulses as he may have been punished for the expression of these in childhood. (Sternbach, 1976)

In a study conducted by Merskey and Spear, it was found that in 200 consecutive admissions to a pychiatric clinic, pain was a symptom of 106. Depression was the most common diagnosis in 85 of the 200 , and pain occurred in 48 of the 85 depressive patients.

"In psychiatric populations, the presence of a pain complaint is about equally likely to predict a diagnosis of anxiety, hysteria or reactive depression, so that patients with pain complaints are somewhat less likely to receive a diagnosis of depression than are those who do. not have such complaints of pain." (Sternbach, 1976).

"Bradley studied the response to antidepressant treatment of two groups of patients; 16 whose pain preceeded the depression, and nineteen whose pain and depression occurred together. In the first group, depression alone responded to treatment, but there was an increased tolerance to pain. In the second group, both the pain and the depression were relieved by the treatment of depresșion." (Sternbach, 1976).

Sternbach states further that "depression is a practice which consists of manipulating others by expressions of dependency and an unwillingness to give gratification to others. It is a form of expressing anger, and thus hostility seems to be sensed by others who cannot quite pinpoint the reasons. The depressive attempts to get support and concern 
from others without incurring the responsibility for reciprocating. The complaint of pain functions in much the same way. When described psychologically, chronic pain and depression seem almost to be interchangeable; chronic pain usually leads to a reactive depression, and a reactive depression frequently results in pain." (Sternbach, 1976).

The Good Samaritan Pain Clinic strongly believes in a phenomenon called "painmanship" coined by Szasz. Szasz uses the term to describe the interaction that takes place between patients and doctors. In this game, the physician's goal is to confirm his professional identity by finding the cause of pain and thus alleviate the patient's suffering. The patient's goal, however, is to gain confirmation of identity as an individual who is suffering from pain by demonstrating undiagnosable pain and extreme suffering. Szasz states that it is as unreasonable to expect the patient to give up his identity and career as it is to ask the physician to do so.

The problem is that the patient insists on medical or surgical treatments to both confirm his identity as a suffering person and as a "professional invalid." It is hard for the physician to differentiate between the patient who really wants to obtain relief and the patient who insists on it but has no intention of getting well.

Sternbach states that many of these patients are not trying to obtain secondary gains, but for many, workmen's compensation, addiction, attention from doctors, or the sick role may be the motivating factor. (Sternbach, 1976). Such a person's actions and interactions are "designed to confirm this identity. His interpersonal interactions take the form of games designed to maintain this identity, and a series 
of such games over time determines the individual's life-style." Sternbach states: "In dealing with a great many pain patients it is clear that certain themes and patterns recur between many patients and the persons important to them. Examples are the "home tyrant." In this case, the pain serves as an excuse and the individual, therefore, gets his way. Further examples: "The professionals" who paid, by workmen's compensation and/or medical insurance for his role. The addict who can continue to take addictive pain killers since he can legitimize taking them through his experience of pain. The person who uses the pain to avoid emotional upsets. (Sternbach, 1976).

DavidA. Swenson tends to agree with Sternbach since he states: "suffering experienced is dependent on the patient's attention to the painful area. The degree of attention is outside the patient's awareness. The suffering is recognized to be the product of some input signal from the periphery and the attention focused on the area of this input. Potential financial reward and security can profoundly increase attention to a painful area. Whether to work in the presence of distress or accept a declared disabled state with financial rewards is a difficult dilemma. The basic human condition tends to force one toward the state of decreased demands. Further complicating this situation, is the pain patient's realization that the family may be better provided for by compensation, which may exceed the patient's previous income.

In our culture, the individual who complains of pain is usually accorded respectful attention by family, friends and employers. The concern of others and decrease of demands becomes intimately associated." (Swanson, Floreen, and Swenson, 1976). 
It is important to emphasize that "the first essential in the treatment of all patients with pain and especially by the psychiatrist, is that the patient should feel that his symptom is regarded as real and not imaginary. Those patients who become anxious, depressed, obsessional, or who develop conversion symptoms as a result of suffering from chronic pain, require reassurance that the intensity for their distress is nevertheless recognized. Occasionally, the enthusiasm and support of a pain clinic following a rather disjointed and ineffective series of consultations with other specialists will rouse the hopes of a patient and at least temporarily ease his pain." Hence, rather than trying to decide whether a patient has psychogenic or somatogenic pain, it is more helpful to describe his problem in psychological and physiological terms. (Sternbach, 1976).

Other studies that have found correlations between neuroticism and chronic pain have been: Pilowsky's and Spencer's: 'IIIness Behavior Syndromes Associated With Intractable Pain"; McCreary, Turner and Dawson: "Differences Between Functional Versus Organic Low Back Pain"; and Swanson, Swenson, Maruta and Floreen's study entitled: "The Dissatisfied Patient With Chronic Pain"; and Earnest Small's Study: "An Investigation into the Psychogenic Basis of the Temporomandicular Joint Myofasical Pain Dysfunction Syndrome." Sternbach and Timmerman's "Human Chronic Pain and Personality; A Canonical Correlation Analysis." Correlations between psychological make-up and chronic pain have also been found in words used by chronic pain patients. Agnes and Merskey found in their study entitled: "Words of Chronic Pain" that patients with pain of organic etiology used sensory-thermal (e.g.; 
hot-burning) words more frequently used than those with pain of psychiatric origin. Female patients with pain attributed to anxiety used sensory-temporal words (e.g.; throbbing) more frequently than those with other psychiatric diagnoses.

Another contrasting study was carried out by Nancy Seres, M.A. Her study was carried out at the Portland Pain Center. It was designed to test the M.M.P.1. as a tool for predicting success of chronic low back pain patients in a non-surgical multidisciplinary treatment center. Two groups of fifteen patients in each were studied. Members with scores on the M.M.P.1. hypochondriasis and hysteria scales of 70 or below represented the normal group. Members with scores of 90 or above represented the abnormal group. Subjects in the two groups were evaluated on a physical exercise of "long sitting to toe" of the Williams flexion Exercises. Patients were evaluated at times of admission, discharge and three months after discharge from the study. No significant differences or improvement between the two groups were found. It was concluded that the M.M.P.I. does not appear to be useful for predicting success of treatment of chronic low back pain patients in multidisciplinary treatment center on a short term basis. (Seres, 1976).

in contrast, Sternbach and Timmerman looked at pre and post treatment M.M.P.I. scores of patients, to look at personality changes associated with the reduction of pain. The study showed that the patients who received surgery showed a greater reduction in the hypochondriasis and hysteria scores than the non-surgery patients. The scales, which show manifest depression, pain preoccupation, and a tendency to play pain games showed no differences between the two groups. 
The post treatment activity on the ward showed that the surgery patients to have increased their activity significantly more than nonsurgery patients. Thus patients in the surgery group showed a greater change toward normality in personality test scores, particularly on neurotic scales than did the non-surgery patients. Thus they concluded that it was the marked decrease in pain which allows a return to normal levels of psychological functioning and that neurotic features so often associated with chronic pain are primarily the consequence of pain and dissipate with pain reduction." (Pain, 1975).

One of the most recent studies found which viewed the correlation between psychiatric functioning and chronic pain was one entitled; "Emotional Adjustment and Chronic Pain" by H. Merskey and D. Boyd.

A standardized data sheet was filled out on 141 patients who had chronic pain, at the National Hospitals for Nervous Diseases, Queen Square and Maida Vale.

The data collected on the patients was, "sex, age, marital status, inpatient or outpatient status, characteristics or patients' fathers and mothers, separations from parents up to age 16, attitudes towards parents, sibs, position in sibline, education, occupation, premorbid personality traits, premorbid neurotic symptomology, medical and surgical past health, psychiatric and psychosomatic health, menstrual history, marital harmony, current attitudes, antecedent emotional stress; and diagnosis.

These variables had responses and sub-categories that were numerically coded and compared with each other giving rise to 2,348 chi squares. Data collected and coded to show features of the pain were: site, side severity, course, duration, frequency of episodes, overall duration of 
pain as a complaint, precipitants, and relieving factors.

The 141 patients consisted of 65 men and 76 women. Seventy outpatients and 71 inpatients. Seventy-one of the patients had an organic lesion. The average age was 44.8 years. One hundred and twenty-seven had severe pain which was chronic. (Average duration was 70.3 months). More women had premorbid anxiety symptoms than men and more women recognized antecedent emotional stress as a precipitant of pain. Of the 89 patients in who a psychiatric diagnosis was made, 55 were women. The distribution diagnoses of these 55 women was: Reactive depression, 43.6\%; Engodenous depression, 10.9\%; hysteria, $23.6 \%$; anxiety, $20.0 \%$; and manic depressive illness, $1.8 \%$.

Principal organic diagnoses were reported by Agnew and Merskey and included causalgia, post-herpetic neuralgia, facial pain, carcinoma, thalmic syndrome, vascular disease, cervical spondyliosis, low back pain, and dental pain.

The description of pain correlated somewhat with physical lesions. "Aching" pain had an organic basis or 26 of the 43 cases; "stabbing" pain in 9 out of 12; and "aching plus stabbing" in 11 out "of 14. On the other hand, "throbbing" pain or "throbbing pius aching" were major complaints of patients with no organic lesion to account for their pain.

Nine patients with lesions and seven without lesions recognized both psychological precipitants and physical ones for their pain. Psychological precipitants alone (without physical precipitants) were recognized by 28 patients who didn't have lesions compared to two with lesions, and physical precipitants alone were reported in 48 patients with lesions and 12 without. 
Emotionally based pain occurred in all six of six patients who reported their fathers as rejecting; in 9 of the 12 patients with mothers who had psychosomatic illness, and in all 4 patients who reported their mothers as punishing.

Three-fourths of the patients with premorbid conversion symptoms had no organic basis for pain, and patients with several of the characteristics of: "reserved, shy, worrier, and nail-bitter" tended to have pain without a lesion. A past history of either psychiatric or psychosomatic illness did not correlate with pain being of non-organic cause. Patients who had more than one or two operations tended to have an organic origin for their pain.

Women with no organic origin for their pain were more likely to have severe pre-menstrual symptoms and dysmenorrhea.

A marriage characterized by upsets, blows, conflicting interests; or separations was more common in the "no lesion" group.

Patients with premorbid obsessive symptoms or obstinate, critical, or combative personality traits or feelings of guilt tended to have fathers who were not warm or affectionate. One-fourth of those fathers who were alcoholic were still described as warm and affectionate. Four patients reported their mothers as punishing but three had premorbid obsessive symptoms. Six patients reported guilty feelings and 5 of them had no organic basis for pain." (H. Merskey and D. Boyd, 1978).

This leads into the next section of the literature search; Modalities used by the Pain Evaluation Clinic which have been evaluated. One modality used is the McGill Pain Assessment Questionnaire. In 1975, Melzack and Timmerman conducted a study entitled: "The McGill Pain 
Assessment Questionnaire: Major Properties and Scoring Methods." In this study, Melzack and Timmerman asked their subjects to classify 102 words from medical literature into smaller groups which describe various aspects of pain. The words were classified into three classes and 16 sub-classes. The second part of the study was to try to determined the pain intensities implicated by the words in each sub-class.

It was found that a questionnaire requires about 15 to 50 minutes to complete. It was found that patients may reject words until one comes up that definitely fits. Generally the patients were found compelled.to choose only appropriate words and that patients are grateful to be provided with words to describe their pain since they wouldn't use such words with their doctor out of fear of being considered psychologically unsound. (Pain, 1975).

Another modality assessed has been Transcutaneous Electrical Analgesia. A study by Richard Sternbach, R. J. Ignelzi, L. M. Deems, and Gretchen Timmerman entitled: "Transcutaneous Electrical Analgesia; A follow-up analysis" was carried out. Subjects were from the pain ward of the V. A. Hospital in San Diego. All had been in pain for at least six months.

While in the hospital, all patients were to use a transcutaneous electrical stimulator for two weeks. Some patients received surgery for their pain during this time. Thus, four groups were to be compared in the study; those who received surgery for pain and used the stimulator, those who received surgery and did not use the stimulator, those who did not receive surgery, those who used the stimulator are to be compared with those who did not. Data used for comparison were; pain estimate: The 
patient's estimate of the severity of their pain on a $0-10$ scale; activity level; anaigesic intake, tourniquet pain test.

All groups showed a decrease in their estimates of pain severity and their analgesic intake. They all showed an increase in their activity levels. An analysis of covariance was performed to assess the specific effects of transcutaneous electrical analgesia. The surgery patients who did not use the stimulator showed a greater decrease in pain after one year than those who did use the stimulator. For non-surgery patients, there were no significant differences in pain estimates after one year. Overall, transcutaneous electrical stimulator can give analgesic effects over a long period of time in certain cases of chronic pain. In patients who have had success in surgery, there is little use of the stimulator. In patients whose surgery hasn't been successful, the transcutaneous electrical stimulator does not reduce pain levels or analgesic intake. and does not increase activity levels.

In patients who are not appropriate for a pain reducing surgical operation, neurostimulators are more effective. Other studies done to look at the effects of transcutaneous electrical stimulator are: "Peripheral Nerve Stimulation in the. Treatment of Intractable Pain." (James Campbell and D. Long, Journal of Neurosurgery, 1976).

Patients from the Pain Evaluation Clinic are occasionally referred to the staff psychologist for either biofeedback or hypnosis to learn to control bloodpressure, heartbeat, pulse, and headache reduction. C. Cedercreutz, R. Lahteenmake, and J. Tulikowa carried out a study entitled: "Hypnotic Treatment of Post Traumatic Headacher." (Bonica, 1976). In this study, patients who had headaches were given hypnosis one to ten times. 
Results showed that $50 \%$ of the group stayed symptom free. Twenty percent were improved, and $30 \%$ had no lasting effect. A correlation was found between the state or depth of hypnosis achieved and the incidence of relief. Another study carried out to evaluate the effectiveness of hypnosis was: ".Evaluation of the Efficacy and Neural Mechanism of a Hypnotic Analgesia Procedure in Experimental and Clinical Dental Pain." Jose Barber and D. Mayer. (Bonica, 1976).

A treatment involving aversive therapy was carried out at the Massachusetts Department of Mental Health. It was entitled: "Aversive Behavior Therapy for Chronic Stomach Pain ; A Case Study. "Legalos."

The subject was a 20-year-old patient who complained of constant burning stomach pain. The Massachusetts Department of Mental Health obtained a full medical history and compared it with a social psychological history. What was found was a strong pattern of emotional stressful events. The following program was devised: Six days a week, appointments were set for three to four minutes duration, an upward sliding fee scale that increased each week the patient's pain failed to diminish, and a blood pressure cuff was placed on the patient's arm to which was attached several fiberglass plates with painfully rough surfaces.

'The blood pressure cuff was inflated at varying rates across trials. It was inflated until he stated the pain equalled the pain in his stomach. Along with increases in arm pain, were reductions in stomach pain intensity. On the 180 th trial, the patient requested a psychotherapy session due to worsening depression. In this session, many previously denied, emotional issues were explored. Behavior therapy continued and the stomach pains declined until they reached a point at which the patient 
was aware of his stomach but not in pain. As psychotherapy increased and depression decreased, the patient became more active socially, more assertive and more spontaneous in expression. (Pain, 1977).

Other Program Evaluative Studies Done. Although the above studies show the effectiveness of specific modalities, it is necessary to emphasize that the Pain Evaluation Clinic finds that a combination of modalities is most effective. The following study discusses evaluation of the multidisciplinary approach:

The study was carried out at the Portland Pain Center in 1976. It involved using 100 unselected, consecutively treated chronic low back pain patients. Each patient had been in the clinic approximately 21 days and seen three months after for follow-up. Most of the patients had sustained injuries while at work and had opened claims with their workmen's compensation at the time of admission. The average age of each patient was 45. Each patient received operant conditioning. (E.g.; "Encouragement and reinforcement of any new behavior that appears to fall in the category of "well. behavior" such as increased exercise tolerance, and reduction of analgesic medications, and a reduction of pain behaviors. Removal of reinforcers for old betiaviors such as complaining of pain, abnormal gait, and dependency, behaviors and reinforcement of behaviors that are incompatible with the old behavior such as encouraging a patient to walk in the hall. Team meetings occurred daily. Patient's progress was maintained and appropriate therapeutic plans were made. Regular spouse groups were held. Exercises were used as a means of teaching appropriate body mechanics to reduce pain. Biofeedback was also used to teach the patient he could control such functions as muscular tension in 
skeletal muscles. Relaxation therapy was also used in helping the patient to relieve tension and gain control over some of the emotional aspects of pain perception. Education in the form of lectures took place daily. Such lectures explained the mechanisms of chronic pain and why surgical procedures couldn't provide the patient with a new back. Lectures also dealt with problems in sexuality with a physical disability and to help show patients how chronic pain effects one's personality. Psychological counseling was also used to help patient's deal with psychogenic aspects of their pain.

Results: At the time of discharge from the program, each patient was out of bed all day and using an upholstered chair for rest. Eighty percent of the patients reported they were no longer seeking medical care for their back problems. (Seres and Newman, 1976).

Another follow-up study of a pain clinic was carried out by Ignelzi, Sternbach and Timmerman. It showed that follow-up analysis of two and three years showed that there were "significant reductions from admission levels in patient's pain estimates and analgesic intake and highly significant increases in activity level, and a very significant decrease in analgesic intake." (Pain, 1977).

A study was also done by $J$. Seres on 36 patients selected for longterm follow-up evaluation on the basis of geographic proximity to the Pain Center. The study is entitled: "Evaluation and Management of Chronic Pain by Non-surgical Means." Joel Seres, R. J. Newman, Ph.D;, Leonard P. Yopse, Ph.D.; and Bonnie Garlington, M.A.

Thirty-six chronic low back pain patients were asked to return to the Portland Pain Center for re-evaluation and re-examination by the 
staff psychologist, physician and physical therapist. The average duration of follow-up was 18.6 months since discharge from the pain program.

Data collected were: Examination of the patient's present industrial claims status, working status, medication taking behavior, active physical measures and the degree to which patients were seeking further medical or surgical care. They repeated the M.M.P.I., the Pain History Index and other questionnaires.

The subjects had a mean age of 44.5 years. The average length of their sickness was 6.3 years with a mean number of 2.1 surgical procedures performed for their pain.

The physical therapist took three measurements of mobility and exercise tolerance: "Long sitting to toes, straight leg raise and knee to chest. The completed various tests and questionnaires were evaluated by the professional staff in regard to overall level of functioning, the seeking of additional care and drug use." (Fletcher 1977).

Results: Three of the 36 patients studied received some surgical procedure on their backs after leaving the pain center.

of the 36 patients studied in the group, five were working full time. Six were working part time or involved in a significant retraining program and 25 remained unemployed.

Patients maintained their gains in mobility, range of motion, and endurance. In each case, the patients who were employed full time, not oniy maintained their gains but improved in range of motion, strength and endurance over the long term. Significant reduction in medication occurred - as did reduction in continuing to seek further medical help and/or surgical care. 
In summary, it appears that the Pain 'Center Program is an effective treatment strategy for the chronically disabled low back pain patient. (Lee J. Fletcher, 1977).

Another assessment of a pain program was conducted at the Mayo Clinic in Rochester, Minnesota. In the study 50 patients were admitted and dismissed between October, 1974 and March, 1975 from the inpatient program at the Mayo Clinic. The intent of the program was to help the patient and family cope with pain more effectively; to teach self treatment methods, and to reduce pain. Three to four weeks of hospitalization were planned. The first three days were devoted to analysis of the patient's problem, level of activity and use of medications.

The treatment consisted of the following: Behavior modification, physical measures, medication management, family member participation, and other psychological approaches.

In Behavior Modification: Pain behaviors (complaints, manipulations, dependency maneuvers) were observed and recorded but approached with a neutral response. The next was increased physical activity where independent functioning and social interaction are reinforced. Subjective pain level; "up time" specific exercises, and the time when mechanical assists (braces, collars, crutches, wheelchairs) not.used were graphed by the patient. Reinforcement of improved function by patient's review of admission videotapes.

Physical measures consisted of explanatory discussions relating physical activities to anatomy: Group and individual exercise periods, development of work-related activities, and assistance that would further independent functioning and self administered physical and/or occupational therapy modal ities; e.g.; heat, etc. 
All pain related medications were given as needed during the evaluation phase; thereafter, they were given at fixed times. After the evaluation phase, the medication is administered in a vehicle with the patient unaware of the drug and dose. Gradual reduction and change of medication. Family member participation; spouse or another important family member participates in the program during the last week of hospitalization; discussions of the patient's pain problem and effect on the family; instruction in application of operant approaches; use of medication and review of family communication.

Other psychological approaches were: group discussions of pain related topics with a videotape demonstration; biofeedback and relaxation techniques and supportive treatment.

Admission criteria are: a complete medical evaluation; no related malignant disease; no specific medical or surgical treatment applicable and acceptance by the patient of the treatment program. (It is important to note that all of the above criteria is identical to Good Samaritan's Program).

Study: Fifty patients were admitted and discharged between October 7, 1974 and March 7, 1975. Ages ranged from 23-73 years. Marital status included 39 married, five divorced, five single, and one widowed. They were treatment (medical) failures and had chronic pain. The typical patient had pain in the low back and leg for seven years with approximately six hospitalizations, two surgical procedures, and various other treatments which all failed. They had not worked for two years and were receiving compensation. 
Medication was a problem. The average patient took three medications and misused one or more. Of psychological problems not related to the pain complaint: three had chemical dependency, 16 had neurosis, one had psychosis, one personality disorder and 34 did not have psychiatric problems. Medically, (unrelated to pain but complicating it) five had hypertension, three had diabetes, three had seizures, two had coronary artery disease, one had post kidney transplant status. Thirty-six showed no medical problem. Of neurological problems: sixteen had radiculepathy, four had arachnoiditis, three had neuroablative residuals, one had neuropath, one had brain stem infarct, 25 negative. of orthopedic problems: twenty-four had mechanical factors, five had degenerative $x$-ray changes, three had pseudoarthrosis, two had spondylolisthesis, two had post amputation, two had brusitis, ten negative, two not seen. (Mayo Clinic Proceedings, 1976).

Upon admission, approximately one-half of the patients were partially ambulatory and needed the use of some mechanical assist.

of the 50 patients, 46 finished the Shipley Institute of Living Scale (vocabulary and abstraction tests); forty-eight completed an M.M.P.I. The Gouch Adjective Checklist was administered to 30 patients on admission and discharge.

The mean on the Shipley Vocabulary lQ equivalent was 107.35. The mean abstraction IQ equivalent was 90.33. Thus each result showed limited intellectual functioning at time of admission.

In the 26 females, the basic M.M.P.1. profile is similar to those patients with a hysterical personality structure. The hypochondriasis (Hs) and hysterial (Hy) scales were elevated considerably beyond the range 
of normality showing evidence of a neurotic personality. Elevation in the psychopathic deviate ( $P d$ ) scale indicates difficulty in interpersonal relationships; possibly family problems related to a long standing pain problem. The elevation of the hypomania (MA) scale suggests much greater restlessness than in the general medical population. The social introversion scale was lower, suggesting that the female pain patient is more outgoing and socially oriented than her general medical counterpart.

The profiles of the 22 males completing the valid M.M.P.I. indicated more general personality deviation than those of the females. The greatest differences occur in hypochondriasis, hysteria, and psychasthenia, the last scale indicating greater anxiety in males than in females. Although significantly deviant in both sexes, the schizaphrenia (SC) scale indicated more bizarre and distracted mentation in the male patients." (Mayo Clinic Proceedings, 1976).

During the hospital course, practically all the patients were characterized by a resistent attitude. In $24 \%$ of the cases, there was total rejection of the program, the patient leaving within the first ten days. "Another $14 \%$ remained for most of the prescribed time but were consistently critical, believed in the need for further surgical procedures, and did not cooperate with the family program. Rejection of the patient was reinforced by attorneys, : family members and other patients.

of the total group, $54 \%$ remained the prescribed time, realized the need to live with some pain, and eventually accepted the program. In most cases, this acceptance developed with staff support.

Only a few of the $62 \%$ who were abusing their medications acknowledged their excessive intake and drug dependency. The gradual majority 
of patients were tolerant of gradual reduction of medication or substitution.

Eighteen percent had "fixed unrealistic ideas" regarding the cause, medical findings, staff attitudes, and society's response. The pain complaint completely dominated the patient's thinking and effort was expanded in documenting severity, excessive physical limitations, and need for special consideration. When the belief system was threatened by objective medical data, these patients assumed an adverse, accusatory, and paranoid stance. The delusional belief system continued after dismissal, as manifested by steady correspondence alleging mistreatment or requests for more tests and surgery.

Dramatization of pain, suggestibility, manipulation, symptom addition, or intense physical concern was encountered in $42 \%$ of the patients. Such features diminished after ten to fifteen days. A number of patients rated the intensity of the pain as nine on a scale from $0-10$. Another patient would have a daily list of physical self observations he wanted explained; he would gradually relinquish this pattern with repeated reassurance and his own increased physical functioning.

In the category of psychopathic behavior were $18 \%$ of the patients who were without apparent anxiety or depression but used their hospitalization to reduce the threat of divorce or to improve their case for litigation or compensation.

Depression/Anxiety: Dyspheria in the form of depression and anxiety mixed, predominated in $22 \%$ of the patients. (Mayo Clinic Proceedings, 1976). Group interaction had major impact on the treatment course of the individual. Participation of family members was a necessity in the program. Patients were reassured by their relative's reinforcement and 
and improved drug free function.

Overall improvement was noted in $27(54 \%)$ of the patients. Improvement was based on change in three categories: Attitude modification, medication reduction and physical functioning improvement. Twentyseven patients achieved. improvement rated as moderate to marked in all three categories. Also, in this group, various specific categories relating to treatment outcome were reviewed. This is subjective pain level; "up time;" body-pain behaviors, facial vocal pain behaviors, dependent-manipulative behavior.

'The program was least successful in reducing subjective pain levels. The change in "up time" was, less impressive because the patients immediately increased their activity. on admission in an effort to comply with the program's scheduled activities.

Greatest success was in modifying the patient's communication of pain behavior to others, in reducing of analgesic-sedative drugs and in achieving independent physical functioning." (Mayo Clinic Proceedings, 1976).

Six months later, after these patients had been discharged, David Swanson, M.D., Alice Floreen, M.A., and Wendell M. Swenson conducted a follow-up study.

At time of discharge $(54 \%)$ of the admitted patients had moderated to marked overall improvement. "The failures included 16 patients who had left the program early, usually because they were dissatisfied with the treatment approach. Of the 34 patients completing the recommended program, 27 (79\%) improved." (Mayo Clinic Proceedings, 1976). 
"Data for this study were obtained by a queștionnaire that was sent three to six months after dismissal to the 34 patients who completed the program. Twenty-one of the patients who had moderate or better improvement at the time of dismissal, participated in the follow-up. Five patients said their pain didn't last as long or was less intense, or both at the time of discharge. In ten of the patients, the pain was unchanged, six said it lasted longer or more intense than at dismissal. Six didn't respond. The average subjective pain level (on a scale of 0-10) for 24 hours was 4.3 at dismissal and 5.1 at the time of follow-up. Medication used at follow-up was the same or reduced from that at dismissal in 15 patients; six were using more medication than at dismissal.

Seventeen patients had not sought medical treatment for their pain problems since dismissal. Of the other four who responded, two had been hospitalized and two had returned to physicians for treatment. Five were working full time, 12 had an increase in work activity, four noted no change and continued impaired functioning.

Nine said their problems with sleeping diminished or they had no problems sleeping. Nine had some other problem and it was unchanged from the time of dismissal. Three patients had more problems sleeping than they'd had before dismissal. Appetite was improved or showed no problem in 18 patients and was less satisfactory in one. Two had some other problem that was unchanged. Eleven said their energy level had improved but eight said it was unchanged and two said it had decreased.

Subjective mood was rated on a 0-10 scale. Zero being deep depression and ten to the highest point of well being. The mean on dismissal was eight and on follow-up, seven. 
In terms of overall improvement, eight had increased improvement, nine had sustained the level of improvement they'd had at dismissal, and four had diminished improvement.

All eight regarded as unimproved at dismissal participated in the follow-up. One had diminished pain, had improved functioning, needed no additional medical care, and thought she'd benefited from treatment. The remaining patients reported continued problems. Four were dissatisfied with their treatment program and continued to emphasize this during follow-up. Seventy-nine percent showed improvement at completion. Fifty percent showed improvement at follow-up since those not responding were considered treatment failures.

In March, 1977, Archives of Physical Medicine and Rehabilitation discussed a study carried out by Harold Gottlieb entitled: Comprehensive Rehabilitation of Patients Having Chronic Low Back Pain.

The study included patients having chronic low back pain who had not responded to surgical or conservative management rehabilitation. The patients consisted of blue and white collar.workers of low to middle income. Their average age was 43 years. Each patient had had one to eight surgical procedures and had been disabled from six to fifteen years. Forty-three of the 72 patients involved were on workmen's compensation; seventy had a medical diagnosis of organic involvement related to the lower back, and 71 had severe to moderate psychopathology. All of the patients were unemployed and unemployable at the time of admission and had received previous medical treatment.

All 72 patients participated in an extensive rehabilitation program using the following treatment modalities: biofeedback training, individual group and family psychotherapy; self medication reduction program, 
patient participant case conferences; physical reconditioning program; vocational counseling; planning placement and referral program, education lectures; and a therapeutic milieu designed around relaxation, recreational activities and socialization.

Success was defined as an average rating of 3.0 on the ten functional improvement $(F I)$ and $c l i n i c a l$ assessment (CA) with an increase of at least one on each four point scale. Fifty of the 72 patients at discharge were considered program graduates. This improvement remained to be so at one month follow-up with 33 out of 40 follow-up patients achieving 3.0 or better.

At one month follow-up, $95 \%$ of the patients had maintained successful levels of restoration. Eight were employed, 23 were in training programs, seven were prepared to enter employment training. When a sample of 23 patients were contacted after discharge, 19 (82\%) were either employed or in training." (Gottlieb, 1977).

Another follow-up study was conducted at the Department of Neurosurgery at the University of Minnesota to assess their two week "minimodification" program. The program basically was a condensed version of the University of Minnesota's six week pain program which is based on Wilbert Fordyce's methodology.

Four to six patients were admitted into the program as a group. The first week consisted of lectures, discussions, helping individuals comprehend the nature of chronic pain. Emphasized particularly were: "The impact of emotional and social factors including loss of hope and trust, depression, family and community interrelationships, spiritual inertia, the effect of interminable legal negotiations related to compensation and disabiltiy, and the influence of drugs in further complica- 
ting the pain program. Family members were encouraged to attend the group sessions as frequently as possible. A physical therapy program was also carried out during the first week to gradually increase each patient's activity level. At the end of the first week, patients began to identify their own life problems and outlining tentative goals to make changes. The goal attainment scale was one of the measures used to teach problem solving skills.

During the second week, the discussion groups, detoxification and activity program were continued. Each patient also had intensive individual and family counseling to clarify the nature of their problems and to agree on feasible future plans.

The follow-up study involved mailing one hundred and thirty-eight questionnaires to patients who completed the program. of these $71 \%$ (98) questionnaires were completed and returned.

Forty-seven out of ninety-eight patients were not actively seeking medical treatment for pain following discharge. The other $52.1 \%$ included patients who were forced by insurance companies to have routine follow-up. Forty-poinț-eight percent were working in some capacity before the program. After the program, $71.4 \%$ were working in some capacity. The number of people not working before the program was $59.1 \%$. After the program, $24.4 \%$ were not working.

Before the program, $10.2 \%$ had a paid job, $29 \%$ were in school, $37.7 \%$ were involved in housework, and $0 \%$ in community and other kinds of work. After the program, $34.6 \%$ had a paid job, $15.3 \%$ were in school or retraining, $40.8 \%$ were involved in housework, $12.2 \%$ were involved in community work, and $17.3 \%$ were involved in some other kind of work. 
In regard to social emotional: $2.6 \%$ stated they were more positive, optimistic, and less depressed; $6.1 \%$ said they had better control over their life; $14.2 \%$ said they learned to live with their pain; one said he had no pain; $7.1 \%$ stated they were more depressed; $1 \%$ said more nervous; $5.1 \%$ more impatient with others, irritable, and/or suspicious; $32.6 \%$ had no change, $12.2 \%$ no response; $30.6 \%$ had an improved relationship with their spouse, $28.5 \%$ had an improved relationship with their children; $5.1 \%$ had a deteriorated relationship with their children; $19.3 \%$ had an improved relationship with their families; $26.5 \%$ had an improved relationship with their friends; $8.1 \%$ had a deteriorated relationship with their friends; $10.2 \%$ had an improved relationship with their co-workers; $1 \%$ had a deteriorated relationship with their co-workers; $10.2 \%$ reported having an improved relationship with others; $1 \%$ had a deteriorated relationship with others.

The mini-modification program also consisted of a medication reduction and a progressive exercise program.

It was concluded that the mini-modification program can be "effective for patients who can understand the information and start to form the necessary tools to cope with problems following discharge. Patients who cannot develop appropriate insight can only be treated effectively in a prolonged program with more of an operant conditioning focus." (A. Archarya; M. A. Michaelson, D. L. Erickson, M.D., "Use of a Problem Solving Approach in the Treatment of Chronic Pain.", 1978).

The most current relevant study found was one entitled: "A Pilot Study of the Treatment of Outpatients with Chronic Pain: Symptom Control, Stimulus Control, and Social Intervention." The study was 
conducted by M. Khatami and J. A. Rush at the University of Oklahoma Health Sciences Center.

The study presented the results of an outpatient treatment program consisting of three parts: Symptom Control - which is designed to help the patient learn to "modify" the nature and severity of his pain. The chronic pain patient develops a sense of hopelessness, helplessness, and meaninglessness about his pain and low self-image. Symptom control is designed to reverse this helpless and hopeless attitude by teaching the patient to master or control his pain. All patients received relaxation training with home practice or electromyographic biofeedback. Half of each session is devoted to symptom control for approximately the first ten weeks of treatment.

The second phase, called stimulus control, consists of cognitive modification methods with which the patient leans to change the way in which he evaluates and responds to his pain and other stressful events. Personal beliefs dictate how internal and external stimuli are interpreted and given meaning. These interpretations are evident in the patient's stream of consciousness (his cognitions). These cognitions may result in high anxiety, muscle tension, and other psychological responses. If personal beliefs interact with environmental events to cause cognitions and consequent somatic and psychological responses, then modification of these cognitions and beliefs should change how the patient evaluates and responds to events perceived as painful.

The patient learns to identify irrational and distorted cognitions or thinking and associated events. He learns to identify underlying personal beliefs upon which these cognitions are based, and also to 
change both the distorted thinking and personal beliefs. The patient learns to more realistically evaluate events or stresses and respond more appropriately to them. The patient identifies events that cause or increase pain and keeps track of the consequences of pain on personal, family, work satisfaction, and other activity. The patient also writes down cognitions associated with increased pain and/or dysphoria. He/she learns to reappraise reality and correct these mal-adaptive, unrealistic cognitions, and the underlying misconceptions or beliefs during the sessions and homework assignments.

The social system intervention treatment is designed to change interpersonal reinforcements for pain and non-pain behavior. Interpersonal payoffs for pain include attention and concern from other people and avoidance of occupational, familial and/or sexual responsibilities. Intervention consists of explicit instructions to family members to modify the positive and negative reinforcers for pain behavior, or structured family therapy. The therapist gives instructions to family members to provide interpersonal reinforcement; (attention, concern, lack of attention) depending on whether the patient demonstrates pain behaviors. Non-pain behaviors are reinforced by the therapist while he pays less attention to pain related behaviors." (Khatami, 1978).

Subjects used in the pilot study were patients who had been referred from the Center for Pain Control and the Department of Psychiatry at the University of Pennsylvania. All of the patients had a medical evaluation previous to the study. Patients were first evaluated at the beginning of the study, after sixteen weeks, and at the end of the study. Six outpatients started the treatment, one stopped therapy after the first 
session. Pain symptoms were present two to twenty-eight years before treatment. All of the patients had had previous therapy in the form of analgesic or psychotropic medications or surgery.

Therapy took place weekly for one hour. Each patient received approximately 35.8 sessions over approximately thirty-five weeks. Evaluations consisted of the patients self reports, including the symptom check list 90 , the Beck Depression Inventory, Hopelessness scale, and weekly ratings of pain, anxiety, depression, work and family satisfaction using a modified Visual Analogue Scale. Each patient kept a detailed record of time, frequency and severity of symptoms and recorded their analgesic medication intake on a daily basis.

Five of the six patients who started therapy, finished treatment and returned for follow-up evaluations at six and twelve months after treatment termination. No patient showed a worsening in hopelessness, pain depression, or medication intake at time of follow-up. In comparison to pre-treatment, significantly decreases in pain, hopelessness, analgesic medication intake and depression were found by the end of treatment. None of the patients were in treatment for pain during the follow-up period. These results remained at six and twelve month follow-up times.

These studies indicate, it appears, that there is a positive value in looking beyond physical symptoms in the treatment of chronic pain. 


\section{METHODOLOGY}

The first step in the study was to decide the study sample. It was decided to include all patients who had been through the pain clinic, and had taken the Minnesota Multiphasic Personality Inventory both at admission to the program and at the end of the program, who had completed daily logs during the time they were involved in the program, who had taken Ro-Coms during the program, and those who had filled out the McGill Pain Questionnaire during the program. Essentially, those patients who were chosen were all those who had been involved in pain evaluation and treatment of some form in the program.

The researchers then identified all quantifiable variables. That is, they translated the variables into numerical form and agreed with the staff on their significance. The third part involved was organizing them into the following categories: testing data, medical, etc. (See Appendix). The rationale for such action was to simplify and organize the arrangement of variables for tabulation. After this was completed, coding sheets were designed in order to figure out how to get the variable information into the coding sheets in numerical form. Files of patients who were to be studied were then alphabetized and given a code number. All pertinent variable information was then extracted from each patient's file and entered on the code sheet. The data on the code sheet was then keypunched and then entered on the computer. A data dictionary is in the Appendix on how the data was translated into the computer.

A letter was then sent to each patient. The letter stated that the pain clinic was doing a study to measure it's effectiveness and why it was being done. The letter also included a dime to go towards postage 
coverage so that patients could return the post card. The purpose of the post card was to confirm addresses. Ninety-six patients returned the post card. It was decided to use only these patients as the study sample.

The next step was to mail all ninety-six patients a packet containing a personal data form, a rotter internal-external locus of control scale, an M.M.P.I., a patient data base system questionnaire (Ro-Com), six McGills, three daily logs. A transcutaneous stimulator questionnaire was sent to those patients who had received TCS in the program. A cover letter with directions on how to complete the materials accompanied the materials. Approximately a week later, all patients were telephoned to see how they were progressing. Complete results were obtained on fiftyone patients.

Terms used in the study which are not usually understood are:

1. Biofeedback - is a term used to describe a process of learning to control internal bodily functions through the use of electrophysiological monitoring devices. A patient can learn to control important bodily functions such as heart rate, blood pressure, peripheral circulation, muscle activity, brain waves and other functions previously bel ieved to be out of reach of conscious control mechanisms.

2. Chronic pain - pain that has endured six months or longer. 3. Daily Logs - are recording sheets given to the patient so he/she can write down how many hours are spent sitting, standing, and reclining. Also to indicate, on a scale of 1-10, his/her pain intensity during each activity. There is also a section to indicate the number of drugs taken and a section to record the times a stimulator was used. 
4. MCGill Pain Assessment Questionnaire - is a method for measuring pain intensity, frequency and qualitative changes at the beginning and end of each clinic visit. A comparison of data at the beginning and end of treatment shows that the patient was experiencing significantly more pain intensity. Also, this measure reflects a qualitative increase in the variety of painful descriptions of sensations over the treatment period. The McGill includes the Present Pain Index (PPI) which is a measure of the patient's present perceived pain, three classes of word descriptors used to clarify subjective pain experience, and the visual analogue scale which is a linear measure of their pain.

5. Minnesota Multiphasic Personality Inventory (M.M.P.I.) - a personality test which yields scores on a series of scales. The test is aimed at characterizing what a person has. It is assumed that what a person has shows what a person does. Scales of hypochondriasis, (HS) depression, (D) and hysteria, (HY) are usually involved in studies of pain. The high hypochondriasis person is more inclined to be interested and concerned with personal health than the average person. High scorers are sour, pessimistic and whiney. They question doctors ability and go from doctor to doctor rarely being satisfied. The depression scale tells something about how the person sees himself and what satisfactions he's getting out of life. The Hy shows repression and denial. High scorers are immature, naive, self centered, shallow, lacking in insight and depth. They are imaginable and uninhibited in social situations with a strong need to be liked. They have little insight into their behavior. The $F$ scale shows whether or not there is confused thinking. A high $F$ scorer may put himself down, or a compulsive person who becomes self- 
critical. The person can be moody, self-defensive, rationalizing and sloppy.

6. Neurosis - an emotional disorder "characterized by loss of joy in living and an avenue of defense mechanisms against anxiety." (Ruch and $\mathrm{Z}$ imbardo, 1970 ).

7. Pain - is the subjective experience of noxious stimuli. It is an interactional, concept, composed of physiological and psychological components.

8. Pain behaviors - behaviors which help to avoid an anticipated aversive emotional, social or interpersonal consequences which can increase or decrease depending on how the environement responds to them. Examples are: wincing, moaning, overly cautious movements or verbal pain complaints.

9. Psychogenic pain - "pain which is better described and under-. stood in psychological rather than in physical language. (This usually means that an adequate explanation in psychological terms can be given." (Sternbach; 1976).

10. Reinforcer - "any stimulus that follows a response and increases the probability of an occurence." (Ruch and Zimbardo, 1970).

11. Transcutaneous Stimulation (TCS) - is an electronic device used for the relief of pain. It is thought to somehow scramble the pain message to the brain so the individual can't feel it with the same magnitude and perception as he did originally.

12. Template - is a tool used to score the M.M.P.I.'.s. 


\section{ANALYSIS OF DATA}

In analyzing the data, a basic data description was made. That is, means and standard deviations were calculated for all the variables. Change scores (comparison of pre and post) were calculated on the daily logs and the McGills on the M.M.P.I., we statistically adjusted for the magnitude of the pre test score and then tested whether for those adjusted change scores had a mean equal to 0 . For five variables, we could conclude there were statistically significant changes which will be disucssed in the interpretation of results section. 
RESULTS 


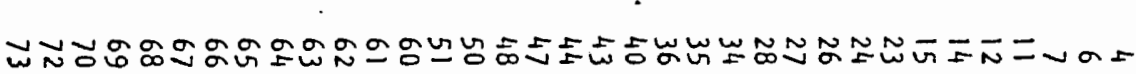

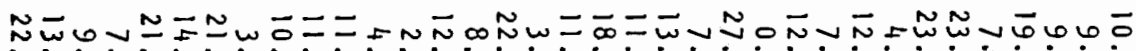

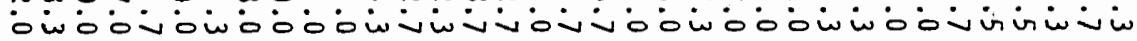

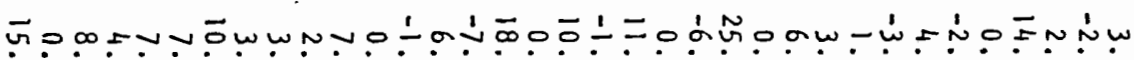
ن

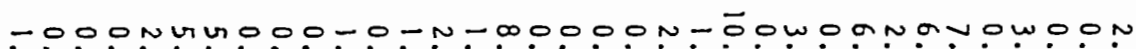

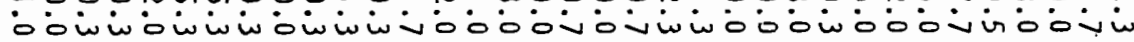

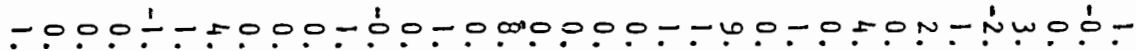

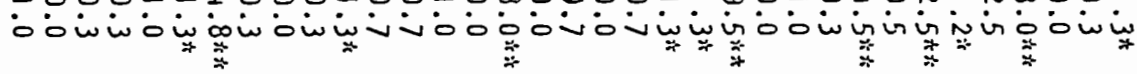

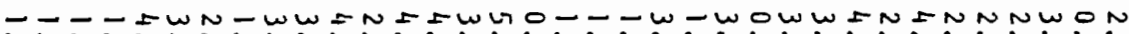
-Ví ó -

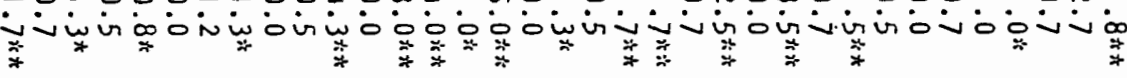

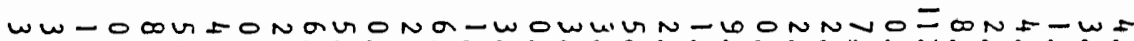
owi ín แ- - 

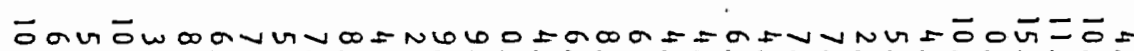

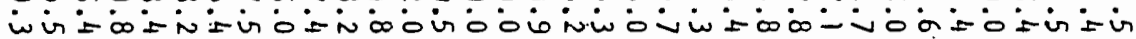
- - - - I - - N

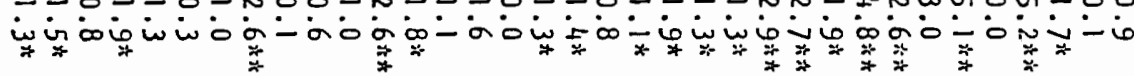

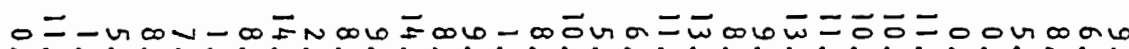

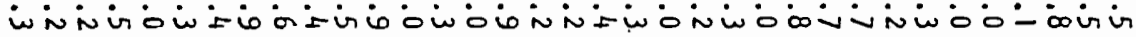

ononmínododwió

anmoanvo OnM0

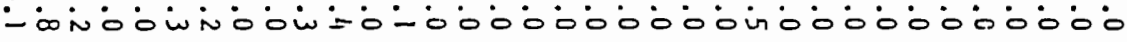
- Ĺ00-100000-0000000000000000000000

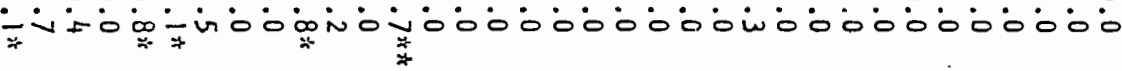

aus

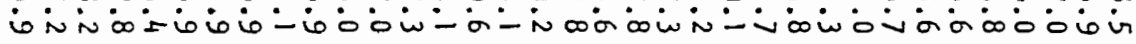

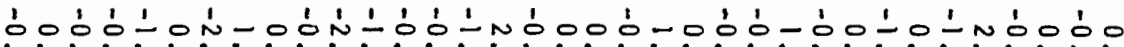

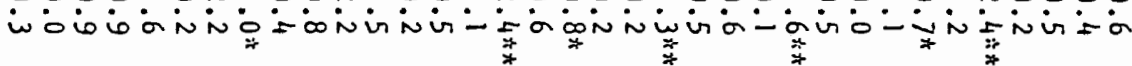




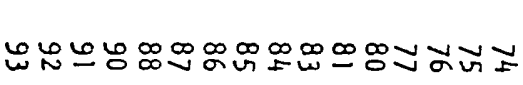

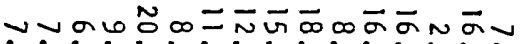
ojovojwivojivioi

ஸ்

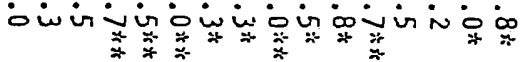

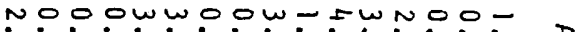

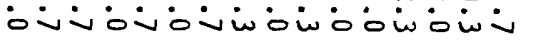

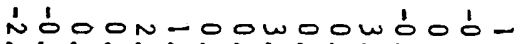

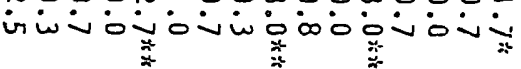

m. س

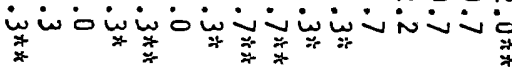

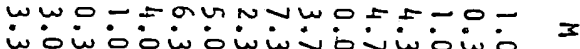

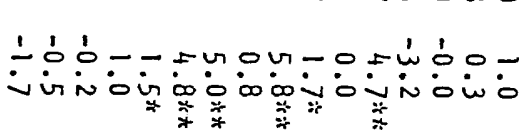

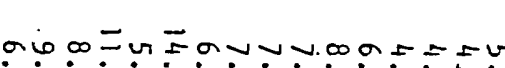
- í $\frac{c}{7}$

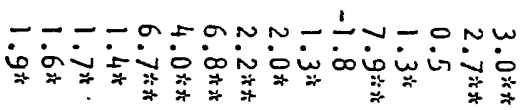
鿷

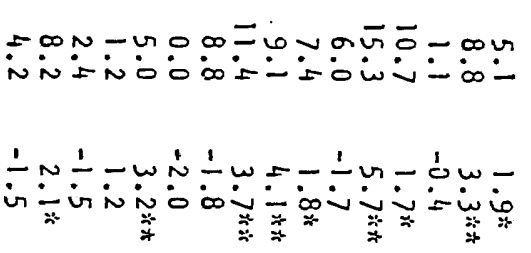

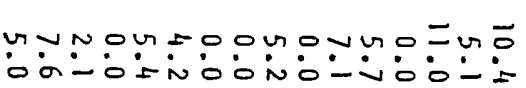
骨

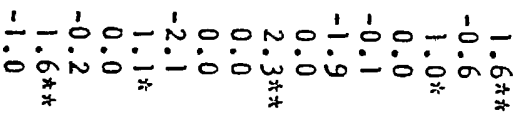

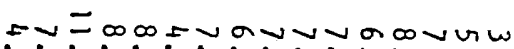

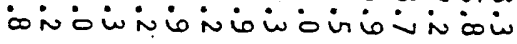

ய்

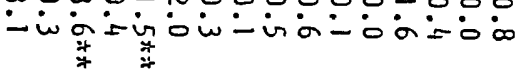




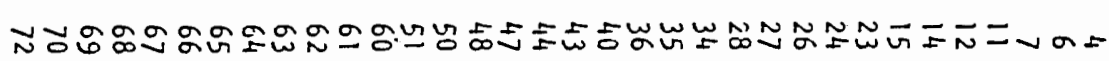

hon

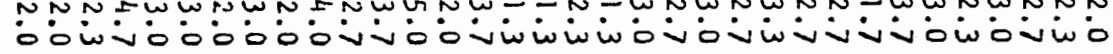
웅

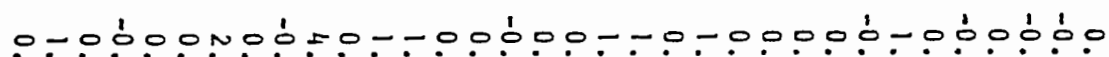

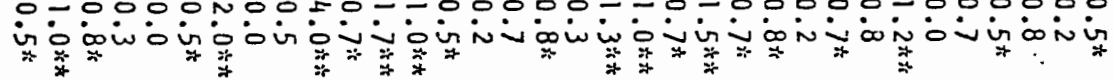
吝

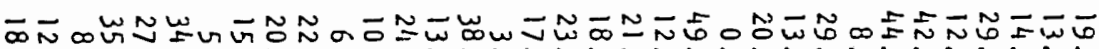

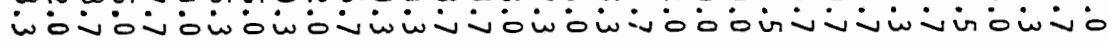

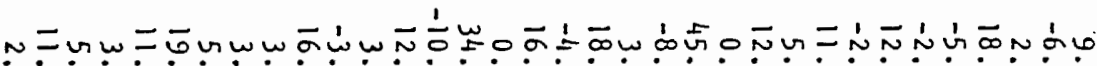
$\infty{ }_{\forall}$

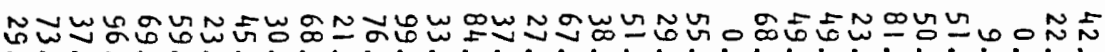

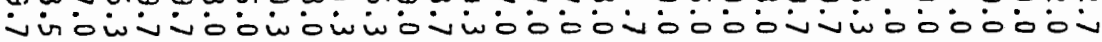

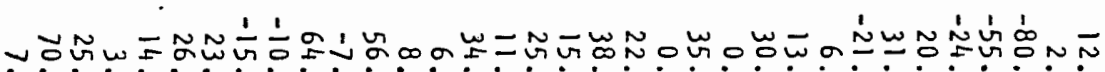

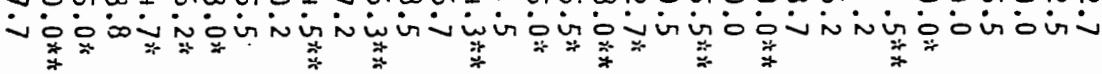

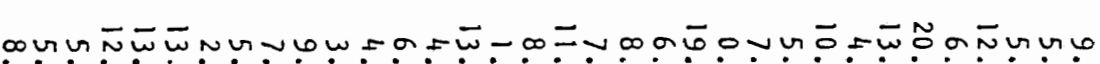
ío: N N

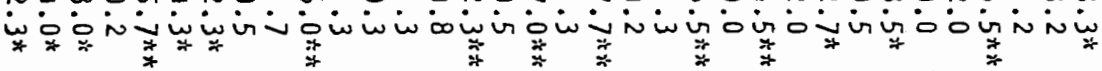

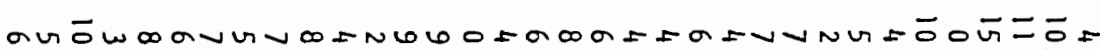

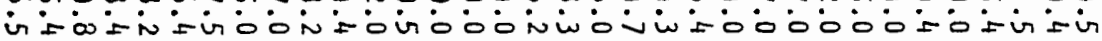

-

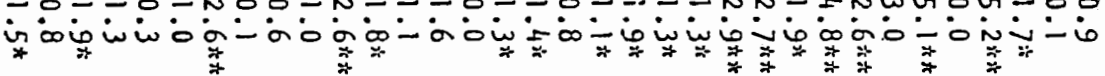

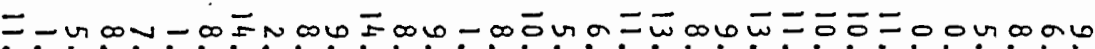

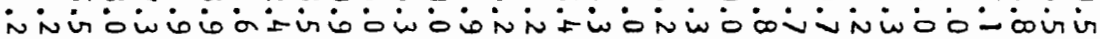

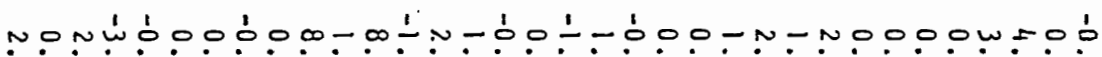

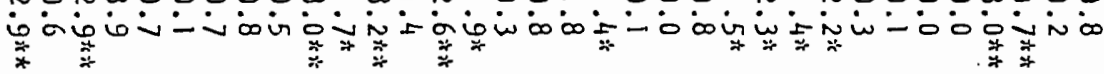
*

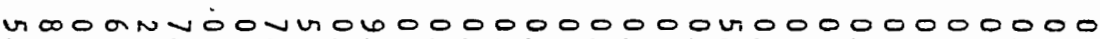

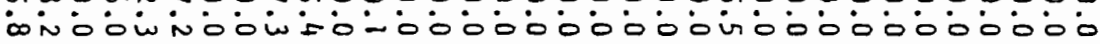

1'́00-100000-0000000000100000000000

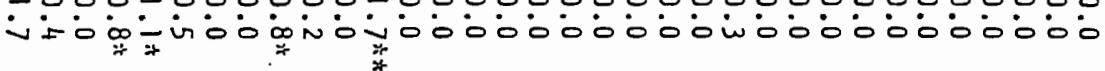

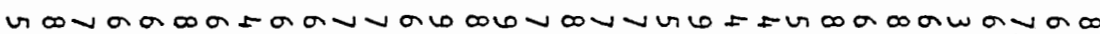

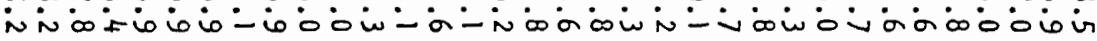

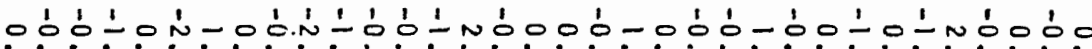

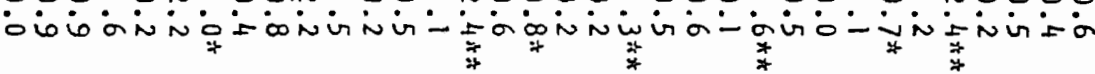




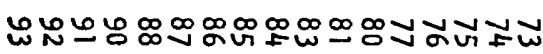

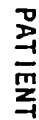

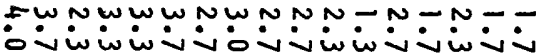
문

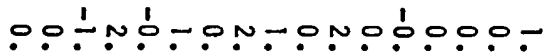

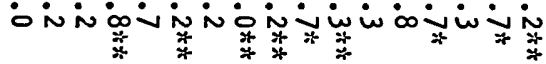

鿷

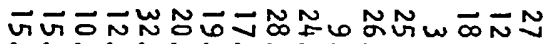

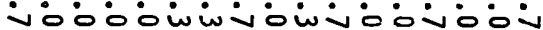

20

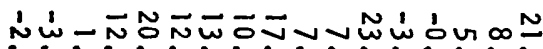

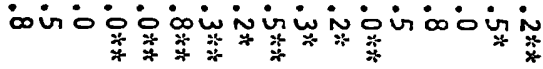

疍

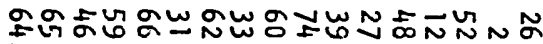

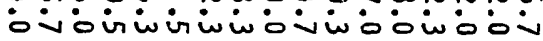

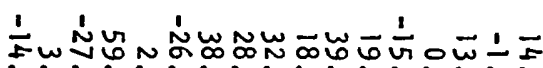

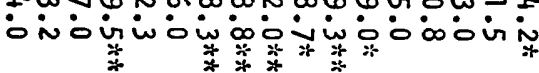

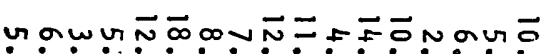
ó

六。

$\sigma 6 \infty$ ニu

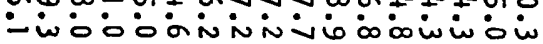

-

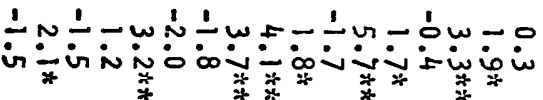

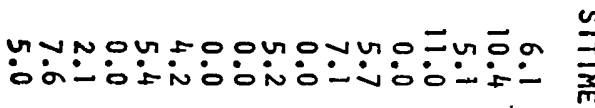

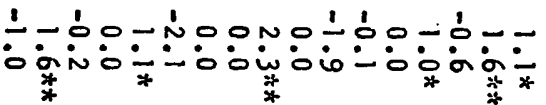

DN = $\frac{n}{\frac{1}{m}}$

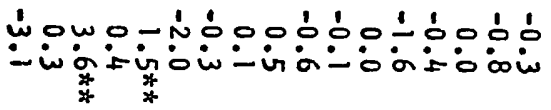




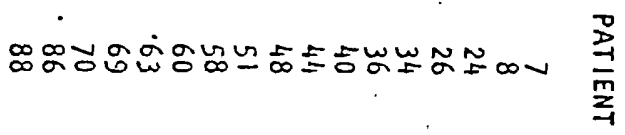

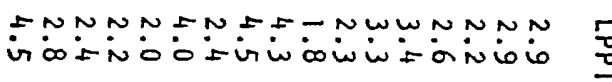

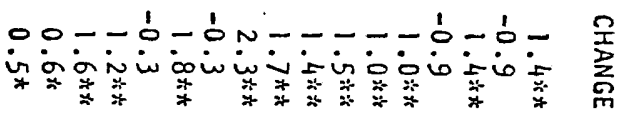

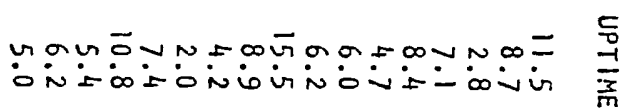

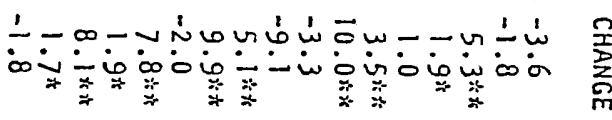

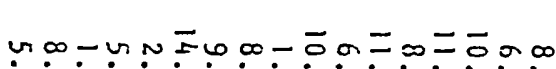

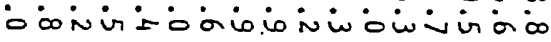

$\frac{0}{\frac{1}{2}}$

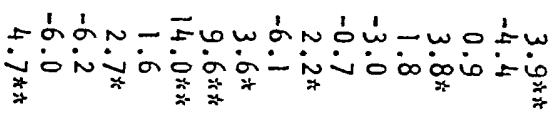

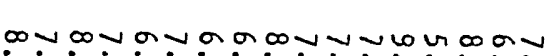

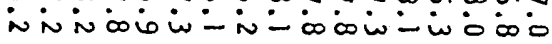

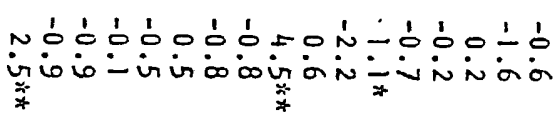

NNNNN NNMWWW Vं $\frac{5}{7}$

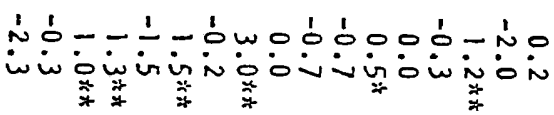

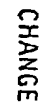

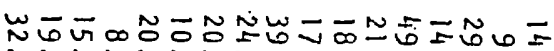

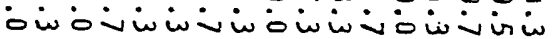
끔

ทั ตฺ io

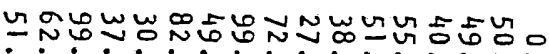
wiói І i in $_{*}$ in in in

ñunvura Fon

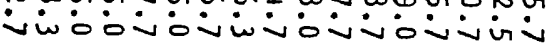




\section{M.M.P.I. PRE-POST CHANGE}

\begin{tabular}{cccc}
$-i=49$ & DEGREES OF FREEDOM & MEAN & $t$ \\
\hline SCALE & 47 & 2.00 & $2.34 *$ \\
$F$ & 47 & -1.84 & -1.90 \\
$K$ & 48 & 0.57 & 0.05 \\
5 & 47 & -0.10 & -0.007 \\
6 & 48 & 3.16 & $2.24 *$ \\
3 & 48 & 1.59 & 1.02 \\
4 & 45 & 4.27 & $2.99 *$ \\
2 & 47 & 1.98 & 1.73 \\
7 & 47 & -2.04 & $-2.55 *$ \\
Lie & 47 & 0.63 & 0.67 \\
9 & 46 & 3.04 & $2.42 *$ \\
1 & 44 & 1.55 & 1.29 \\
8 & & &
\end{tabular}




\section{INTERPRETATION OF RESULTS}

It was decided that the following criteria indicated a success. If one-half of the patient population in the study showed one-half or a full standard deviation change in medications, one-half or a full standard deviation change in uptime. If two or four pain measures have changed, the person can be considered a success.

The sheets labeled "up time and down time" shows that complete data was obtained on fifty-one patients. Fifteen patients are to be considered successes since they moved more than one standard deviation from the mean on the pre test. The latter is the strict criterion. All those patients who moved a full standard deviation are those who have two stars. Those with one star are patients who meet the lenient criteria. The lenient criteria is a positive move of one-half of a standard deviation from the mean on the pre test. When the lenient criteria is applied, an additional nineteen patients can be counted as successes. Therefore, it can be inferred that the patients showed increased activity.

Criteria for success on the sheets labeled: "Daily logs and McGills Pre to Post." is as follows: 1 . If the patient had moved a full standard deviation (as indicated with two stars) on two of the four measures. The four measures are: P.P.I., P.R.I., V.A. and number of words. 2 . If they had moved a full standard deviation on any one of the measures and half of a standard deviation on two of the other three measurements (up time, down time, sleep time and sitting time). 3. If they had moved half of a standard deviation on all four measurements. Twenty-five patients out of fifty-one showed significant change based on the above criteria. Thus it can be inferred that the patients perceived pain had decreased. 
The sheet labeled "pre follow-up change scores on daily logs and McGills" show if there was a change on the daily logs and McGills from entrance into the program to the time of follow-up. Based on the strict criteria, seven patients showed significant improvement out of seventeen: An additional three patients can be considered successes based on the lenient criteria.

The sheet entitled "M.M.P.I. Pre-Post Change" shows that the F Scale, the 3 scale-hysteria, the 2 scale-depression, the 1 scale-hypochondriasis and the Lie scale had significant changes. The lie scale was the only one of these which portrayed an increase rather than a decrease. Thus there was an overall improvement in psychological functioning from entry into the program to completion of $i t$. These findings are consistent with those studies cited in the literature search of this text. For example: Sternbach, 1976; W. Fordyce, 1976; Merskey, 1977; Bonica, 1976 and Seres and Newman, 1976.

Results on medications is unavailable to incorporate within this text, however, the results show that 25 out of 50 patients had significant drug reduction and therefore were viewed as successes. 


\section{CONCLUSION}

Since one-half or more of the patients reached success on each of the above criteria, it can therefore be concluded that the Good Samaritan Pain Evaluation Clinic can be considered a success.

The staff research psychologist and the program director have stated that they cannot cite a specific reason(s) for these changes. They feel that the changes were individualized. That is, the reason for increased activity in one patient may be because he learned, through the program, that he didn't need to. live like an invalid and could function effectively despite his pain. Another patient may have increased his activity level because he got recognition and rewards from the clinic and/or family. Thus, these patients were given similar alternative ways of thinking and dealing with their pain by the clinic but how they perceived why the changes took place varied from patient to patient.

It was also concluded that not any one modality could be seen as better, but that a combination of modalities was the most effective. Thus, the program will not make any significant changes. 
1. Acharya, A., Michaelson, M. A., and Erickson, D.L.: "Use of A Problem Solving Approach in The Treatment of Chronic Pain,: Department of Neurosurgery, Department of Social Services; University of Minnesota Hospitals; Minneapolis, Minnesota, 1978.

2. Agnew, D. C., and Merskey, H.: "Words Of Chronic Pain," Pain, Elsevier/ North Holland Biomedical Press, Volume 2, 2-81, 1976.

3. Barber, Joseph and Mayer, David: "Evaluation of The Efficacy And Neural Mechanism of A Hypnotic Analgesia Procedure In Experimental And Clinical Dental Pain." Pain, Elsevier/North Holland Press, Volume 4, $41-48,1977$.

4. Bonica, J. J.: Advances In Pain Research And Therapy, Raven Press, New York, New York, 1976.

5. Boyd, D., and Merskey, H.: "Emotional Adjustment And Chronic Pain," Pain, Volume 5, 173-178, August, 1978.

6. Campbell, James N., M.D. and Long, Donl in M., M.D. Ph.D.: "Peripheral Nerve Stimulation in The Treatment of Intractable Pain," Journal of Neurosurgery, Volume 45, 692-699, December, 1976.

7. Cedercreutz, Claes, Lahteenmaki, Raimo, and Tulikoura, Jukka: 'Hypnotic Treatment of Post Traumatic Headache," Bonica, J. J., Advances In Pain Research And Therapy, Raven Press, Volume 1, New York, New York, 1976.

8. Ferrer-Brechner, M. T., Brechner, V. L., and McCreary, C. P.: "Correlation of Personality Profile With Pain Syndrome," Bonica, J. J., Advances In Pain Research And Therapy, Raven Press, New York, 1976.

9. Fletcher, Lee J., Pain Management: Symposium on The Neurosurgical Treatment of Pain, Bait imore Maryland, The Williams \& Wilkins Co., 33-52, 1977.

10. Fordyce, Wilbert E., Behavioral Methods For Chronic Pain And 11 lness, C. V. Mosby Company, St. Louis, Missouri, 1976

11. Gottlieb, Harold, Ph.D. et al: "Comprehensive Rehabilitation of Patients Having Chronic Low Back Pain," Archives Of. Physical Medicine And Rehabilitation, Volume. 58, 1977.

12. Ignelzi, Ronald J., Sternbach, Richard A., and Timmermans, Gretchen, "The Pain Ward Follow Up Analysis," Pain, Elsevier/North Holl land Biomedical Press, Volume 3, 277-280, 1977.

13. Khatami, M., and Rush, A. J., "A Pilot Study of The Treatment of Outpatients With Chronic Pain: Symptom Control, Stimulus Control, And Social Intervention," Pain, Volume 5, 163-172, 1978. 


\section{BIBL IOGRAPHY (Cont.)}

14. Legalos, Charles N., "Aversive Behavior Therapy For Chronic Stomach "Pain," Pain, Volume 4, Elsevier/North Holland Biomedical Press, $67-72, \overline{1977}$.

15. McCreary, Charles, Turner, Judity, and Dawson, Edgar: "Differences Between Functional Versus Organic Low Back Pain Patients," Pain, Elsevier/North Holland Biomedical Press, Volume 4, 1977.

16. Merskey, H., "Psychiatric Management of Patients With Chronic Pain," Sampson and Lipton, Grune and Stratton, Academic Press, New York, New York, 1977.

17. Newman .Richard J., Seres, Joel L., Yospe, Leonard P., and Garlington, Bonnie, "Multidisciplinary Treatment Of Chronic Pain: Long-Term Follow-Up of Low Back Pain Patients," Pain, Elsevier/North Holland Press, Volume 4, 283-292, 1977.

18. Pilowsky, J., and Spence, N. D., "lllness Behavior Syndromes Associated With Intractable Pain," Elsevier/North Holland Press, Amsterdam, 1976.

19. Pilowsky, J., Chapman, R. C., and Bonica, J. J., "Pain, Depression And 11 lness in A Clinic Population," Pain, Elsevier/North Holland Press, Amsterdam, 1977.

20. Ruch and Zimbardo, Psychology And Life, Scott Foresman and Company, Glenview, 111 inois, 1970.

21. Sampson, Lipton, Persistent Pain: Modern Methods Of Treatment, Academic Press, New York, New York, 1977.

22. Seres, Joel, M.D., Newman, Richard, Ph.D., Yospe, Leonard, and Garlington, Bonnie, M.A., "Evaluation And Management of Chronic Pain By NonSurgical Means," Pain, Elsevier/North Holland Press, Amsterdam, 1976.

23. Seres, Joel, L., M.D. and Newman, Richard, Ph.D., "Results Of Treatment of Chronic Low Back Pain At The Portland Pain Center," Journal of Neurosurgery, Volume $45,32-36,1976$.

24. Seres;" Nancy A., "The M.M.P.I. As A Predictive Instrument For Treatment of Low Back Pain In A Multidisciplinary Treatment Center," 1976

25. Small, Ernest A., "An Investigation Into The Psychogenic Basis of : The Temporomadnibular Joint Myofasical Pain Dysfunction Syndrome," Bonica, J. J., Advances In Pain Research And Therapy, Volume 1, Raven Press, New York, New York, 1976.

26. Sternbach, Richard A., Pain Patients Traits And Treatment, Academic Press, New York, New York, 1974. 


\section{BIBL IOGRAPHY (CONt.)}

27. Sternbach, Richard A., and Timmermans, Gretchen, "personality Changes Associated With Reduction Of Pain," Pain, Elsevier/North Holland Press, Amsterdam, 1975.

28. Sternbach, Richard A., Ignelzi, Ronald J., Deems, Lydia M., and Timmermans, Gretchen, "Transcutaneous Electrical Analgesia: A FollowUp," Pain, Volume 2, 35-4l, Elsevier/North Holland Press, Amsterdam, 1976.

29. Timmermans, Gretchen, and Sternbach, Richard A., "Human Chronic Pain And Personality: A Canonical Correlation Analysis," Bonica, J. J., Advances In Pain Research And Therapy, Volume 1, Raven Press, 1976.

30. Swanson, David W., M.D., "Less Obvious Aspects Of Chronic Pain," Post-Graduate Medicine, McGraw Hill Publications, Long Prairie, Minnesota, Volume $60,1976$.

31. Swanson, David W., M.D., Swenson, Weldell M., Toshihiko, Maruta, M.D., McPhee, Maicolm C., M.D., "Program for Managing Chronic Pain: Program Description And Characteristics of Patients," Mayo Clinic Proceedings, Volume $51,401-408,1976$.

32. Swanson, David W., M.D., Floreen, Alice C., M.A., and Swenson, Wendell M., Ph.D., "Program For Managing Chronic Pain. 11. Short Term Results," Mayo Clinic Proceedings, Rochester, Minnesota, Volume 51, 409-411, 1976. 
BASIC DATA DESCRIPTION: (Tallied responses;

calculated means, with standard deviations

were performed on all. the following variables.

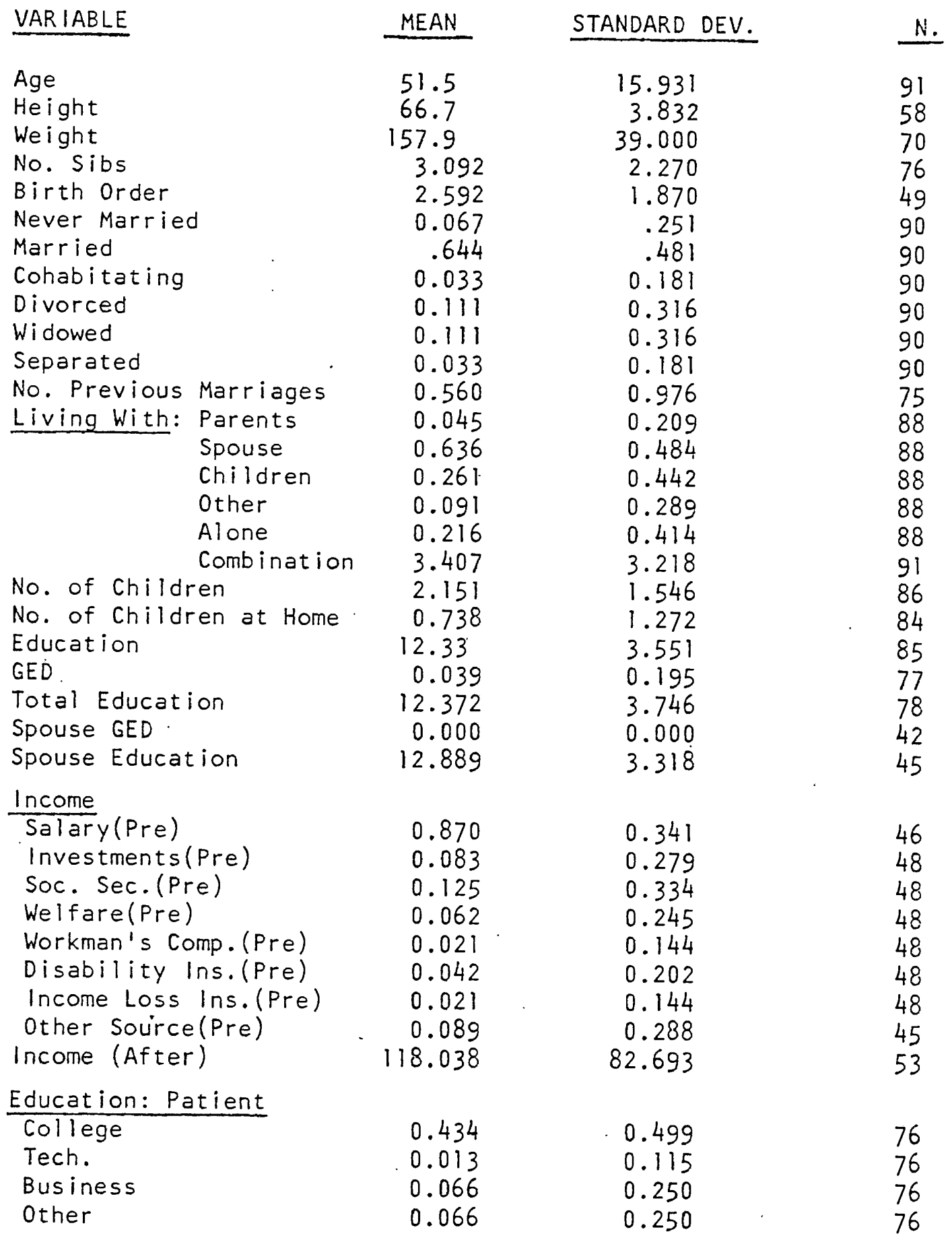


VAR IABLE

Education: Spouse

College
Tech.
Business
Other

Income: Post

Salary
Investments

Soc. Sec.

Welfare

Workmen's Comp.

Disability Ins.

Income Loss Ins.

Other source

$\frac{\text { Occupation }}{\text { Non-Life }}$

White Collar

Managerial

Professional

Homemaker

Laborer

Semi-Skilled

Pre: Full Time

Pre: Part Time

Pre: Retired

Pre: Med. Retired

Pre: Temp. Disabled

Pre: Perm. Disabled

During Full Time

During Part Ime

During Retired

During Med. Retired

During Temp. Disabled

During Perm. Disabled

Post Full Time

Post Part Time

Post Retired

Post Med. Retired

Post Temp. Disabled

Post Perm. Disabled
MEAN

0.302

0.070

0.140

0.092

0.304

0.101

0.342

0.051

0.316

0.190

0.051

0.362

0.584

0.076

0.063

0.215

0.089

0.215

0.278

0.700

0.100

0.050

0.012

0.037

0.000

0.025

0.076

0.051

0.038

0.608

0.000

0.038

0.090

0.064

0.038

0.385

0.115
STANDARD DEV.

N.

43

43

43

43

0.294

0.463

0.304

0.477

0.221

0.468

0.395

0.221

0.485

79

79

79

79

79

79

79

79

Throughout: Who Paid Medical Expenses

\section{Litigation}

SAIF

Wash. L.El.
0.159

0.182

0.057
0.496

0.267

0.245

0.414

0.286

0.414

0.451

0.461

0.302

0.219

0.112

0.191

0.000

0.158

0.267

0.221

0.192

0.491

0.000

0.194

0.288

0.247

0.194

0.470

0.322
79

79

79

79

79

79

79

80

80

80

80

80

80

79

79

79

79

79

79

78

78

78

78

78

78

0.233 
VAR IABLE

Private Carrier

Medicare

Patient

Other

No. of Yrs. in Med. System

Last Hospitalization

Previous Modalities

Medications

Physical Therapy

Surgery

Accupunture

Chiropractor

- Psychology

Other

How Long in Pain

On the Job Injury

Where Pain Located (Pre)

Head
Neck
Anterior Trunk
Posterior Trunk
Rt. Buttock
Lt. Buttock
Genitalia
Rt. Upper Arm
Lt. Upper Arm
Rt. Lower Arm
Lt. Lower Arm
Rt. Hand
Lt. Hand
Rt. Thigh
Lt. Thigh
Rt. Leg
Lt. Leg
$R t$. Foot
Lt. Foot

TOTAL AREA $\frac{\text { MEAN }}{0.545}$

0.318

0.330

0.170

13.909

20.689

1.000

0.637

0.670

0.110

0.209

0.209

0.297

69.176

0.418

0.198

0.330

0.560

0.637

0.593

0.549

0.033

0.220

0.253

0.209

0.198

0.212

0.132

0.505

0.462

0.473

0.451

0.132

0.121

40.011
STANDARD DEV.

0.501

0.468

0.473

0.378

14.013

20.808

$\frac{N}{88}$

88

88

88

38

90

0.000

91

0.483

0.473

91

91

91

91

91

91

91

91

81.564
0.496

0.401

0.473

91

0.499

0.483

0.494

0.500

0.180

0.416

0.433

0.409

0.401

0.328

0.340

0.503

0.501

0.502

0.500

0.340

0.328

91

91

91

91

91

91

91

91

91

91

91

91

91

91

91

91

91

91

23.956 
VARIABLE
Where Pain is Located (Post)

\begin{tabular}{llll}
\hline Head & 0.136 & 0.345 & 81 \\
Neck & 0.272 & 0.448 & 81 \\
Ant. Trunk & 0.432 & 0.498 & 81 \\
Post Trunk & 0.593 & 0.494 & 81 \\
Bt. Buttock & 0.432 & 0.498 & 81 \\
Lt. Buttock & 0.395 & 0.492 & 81 \\
Genital & 0.025 & 0.156 & 81 \\
Rt. Upper.-Arm & 0.136 & 0.345 & 81 \\
Lt. Upper Arm & 0.185 & 0.391 & 81 \\
Rt. Lower Arm & 0.049 & 0.218 & 81 \\
Lt. Lower Arm & 0.099 & 0.300 & 81 \\
Rt. Hand & 0.074 & 0.264 & 81 \\
Lt. Hand & 0.099 & 0.300 & 81 \\
Rt. Thigh & 0.284 & 0.454 & 81 \\
Lt. Thigh & 0.321 & 0.470 & 81 \\
Rt. Leg & 0.321 & 0.470 & 81 \\
Lt. Leg & 0.346 & 0.479 & 81 \\
Rt. Foot & 0.086 & 0.203 &
\end{tabular}

Treatment Modes During Program

\begin{tabular}{lrrr}
\hline T.C.S. & 0.733 & 0.445 & 90 \\
Ind. Couns. & 0.967 & 0.181 & 90 \\
Grp. Couns. & 0.044 & 0.207 & 90 \\
Spouse Ind. Couns. & 0.233 & 0.425 & 90 \\
Spouse Grp. Couns. & 0.067 & 0.251 & 90 \\
Physical Therapy & 0.556 & 0.500 & 90 \\
Diet Grp. & 0.133 & 0.342 & 90 \\
Body Mech. & 0.244 & 0.422 & 90 \\
Biofeedback & 0.167 & 0.375 & 91 \\
Time in P.E.C. & 16.604 & 13.695 & 91 \\
No Surgery & 1.165 & 1.478 & 91 \\
Percent of Body in Pain & 26.407 & 21.474 & 89 \\
Morning Pre. & 0.090 & 0.288 & 89 \\
Afternoon Pre. & 0.124 & 01331 & 89 \\
Evening Pre. & 0.315 & 0.462 & 86 \\
Night Pre. & 0.112 & 0.318 & 86 \\
Morning Post & 0.116 & 0.322 & 86 \\
Afternoon Post & 0.128 & 0.336 & \\
Evening Post & 0.256 & 0.349 & \\
Night Post & 0.105 & 0.308 & 88 \\
Counselor (Pre \& Post) & & & 98 \\
\hline Alison (Pre) & & 0.498 & 91 \\
Ken (Pre) & 0.568 & 0.397 & \\
Alison (Post) & 0.193 & 0.496 & \\
Ken (Post) & 0.582 & 0.285 &
\end{tabular}


VAR IABLE

Reason for Leaving P.E.C.

Staff
Patient
Psychological
Poor Motivation
Accupuncture
Financial
Transportation
Moved
Family Pressure
Returned to Work

MEAN

0.312

0.471

0.508

0.336

0.440

0.369

0.000

0.246

0.296

0.177

0.246

0.062
N.

32

32

32

32

32

32

32

32

32

32 
Field No. Page No.

$01 \quad 01$ Variables

$01 \quad 02$ Variables

0103 Variables

$01 \quad 04$ Modes \& Dates for Treatment

$01 \quad 05$ Mileage

M.M.P.I.\& IE

Field No. Page No.

$02 \quad 01$ Variables \& Unit of Measure

MCGILLS

Field No. Page No.

03

01 Variables \& Unit of Measure

DAILY LOGS

Field No. Page No.

$04 \quad 01$ Variables \& Unit of Measure

DIAGNOSIS \& SYMPTOMS

Field No. Page No.

$\begin{array}{lll}05 & 01 & \text { Diagnosis \& Symptoms } \\ 05 & 02 & \text { Surgeries \& Diagnostic } \\ 05 & 03 & \text { Drugs }\end{array}$

\section{DESIRED CHANGE}

Field No. Page No.

$07 \quad 01$

STIMULATOR TIMES

Field No. Page No.

$08 \quad 01$

RO-COMS

Field No. Page No.

$09 \quad 01$ 
59

RE M.M.P.I. (F \& HS SCALE)

Field No. Page No.

$$
\begin{array}{lll}
14 & 01 & \text { F Scale } \\
14 & 02 & \text { HS Scale. }
\end{array}
$$

POST M.M.P.I. (F \& HS SCALE)

Field No. Page No.

$$
\begin{array}{lll}
15 & 01 & \text { F Scale } \\
15 & 01 & \text { HS Scale }
\end{array}
$$

RE M.M.P.I. (D\& BY)

Field No.

$$
\begin{array}{llr}
19 & 01 & \text { D Scale } \\
19 & 01,02 & \text { HY Scale }
\end{array}
$$

POST M.M.P.1. (D \& HF)

Field No. Page No.

20

20

$$
\begin{array}{ll}
01 & \text { D Scale } \\
01,02 & \text { HY Scale }
\end{array}
$$


CONTENTS

DEMOGRAPHIC FIELD - FIELD NO. 1

PG.\# VARIABLES

Sex

Age

Height

Weight

Siblings

Birth Order

Marital Status

Previous Marriages

Persons Whom Living With

Children

Children at Home

Grade \& High School

completed

G.E.D.

College

Tech. School

Business School

Other

Spouse's Education

G.E.D.

College

Tech. School

Business School

Other

Income Before Development of Pain

29

30

31

32

33

34

36,37

39,40

42,43

45

47

48

49

50

52,53

55

57

58

59

60

Salary

Investments

Social Security

Welfare

Workmen's Compensation

Disability Insurance

Income Loss Insurance
66

67

68

69

70

71

72
UNIT OF MEASURE

Male 1 , Female 2

No. of Years

No. of Inches

No. of Pounds

No. of siblings

No. in Which Patient Falls

1. Never Married

2. Married

3. Cohabitating

4. Divorced

5. Widowed

6. Separated

No. of Previous Marriages

1. Parents

2. Spouse

3. Children i Yes

4. Other

2 No

5. Alone

No. of Children

No. of Children at Home

No. of Years Completed

i. Yes 2. No

No. of Years

No. of Years

No. of Years

No. of Years

No. of Years of Grade and

High School

1. Yes 2. No.

No. of Years

No. of Years

No. of Years

No. of Years

Ten Thousand Dollars Per Year Thousand Yearly

Hundred Yearly

1. Yes 2. No

1. Yes 2. No

1. Yes 2. No

1. Yes 2. No

1. Yes 2. No

1. Yes 2. No

1. Yes 2. No 


$\begin{array}{ll}\text { PG.\# } & \text { VARIABLES } \\ 1 & \begin{array}{l}\text { Other } \\ \text { Income Source at P.E.C } \\ \text { Intake }\end{array} \\ 2 & \text { Salary } \\ 2 & \text { Investments } \\ 2 & \text { Soc. Sec. At time of } \\ 2 & \text { Welfare P.E.C. } \\ 2 & \text { Compensation Intake } \\ 2 & \text { Disability Insurance } \\ 2 & \text { Other Loss Insurance } \\ 2 & \text { Occupation (Type of Work) }\end{array}$

COLUMN UNIT OF MEASURE

2 Lifting
2 Non-Lifting
$2 \quad \begin{aligned} & \text { Before Devel. of Pain } \\ & \text { Cond. }\end{aligned}$
$2 \quad$ At Time of P.E.C. Intake
$2 \quad$ At Time of P.E.C.
Discharge

2 D. V.R.

2 Open Case

2 Closed Case

2 Training

2 Involved in litigation

at P.E.C. Intake

WHO WILL PAY FOR P.E.C. PROGRAM

73

75

76

77

9

10

11

12

13

14

15

16

18
19

20

22

23

24

26

27

28

1. Yes 2. No

Ten Thousand

Thousan

Hundred

1. Yes 2. No

1. Yes 2. No

1. Yes 2. No

1. Yes 2. No

1. Yes 2. No

1. Yes 2. No

1. Yes 2. No

1. Yes 2. No

1. White Colar

2. Managerial

3. Professional

4. Homemaker

Type

5. Laborer

6. Semi-Skilled

7. Skilled

8. Service Person

1. Yes 2. No

1. Yes 2. No WORK STATUS

1. Full Time

2. Part Time

3. Mandatory(Age Related)

4. Medical Retirement

5. Temporarily Disabled

6. Permanently Disabled

Pick

One

7. Not Employed

30
2 Saif

2 Wash. $L \& 1$

2 Private Carrier

2 Medicare

2 Patient

2 Other
1. Yes 2. No

1. Yes 2. No

1. Yes 2. No

1. Yes 2. No

1. Yes 2. No

1. Yes 2. No

1. Yes 2. No

1. Yes 2. No

1. Yes 2. No

1. Yes 2. No 


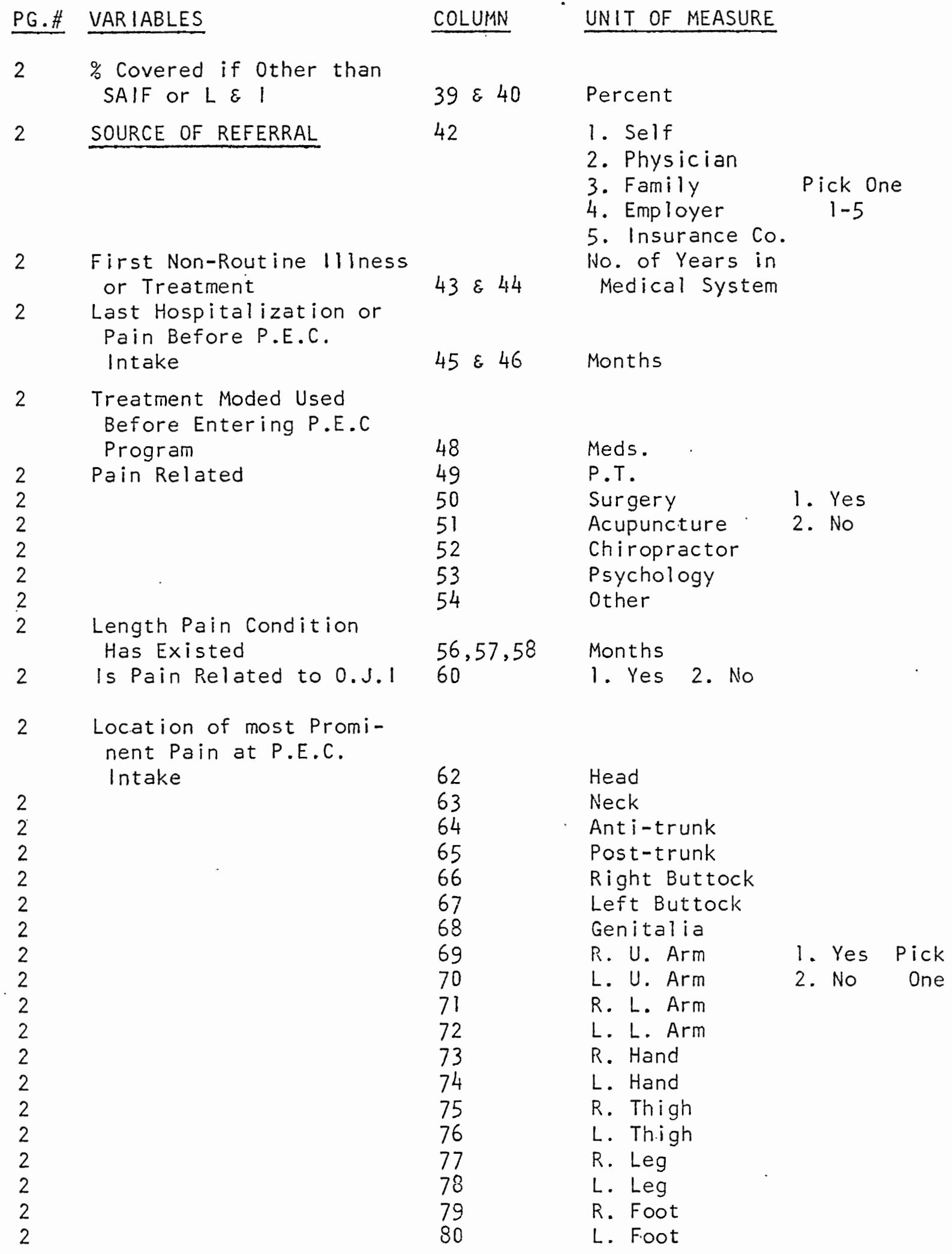




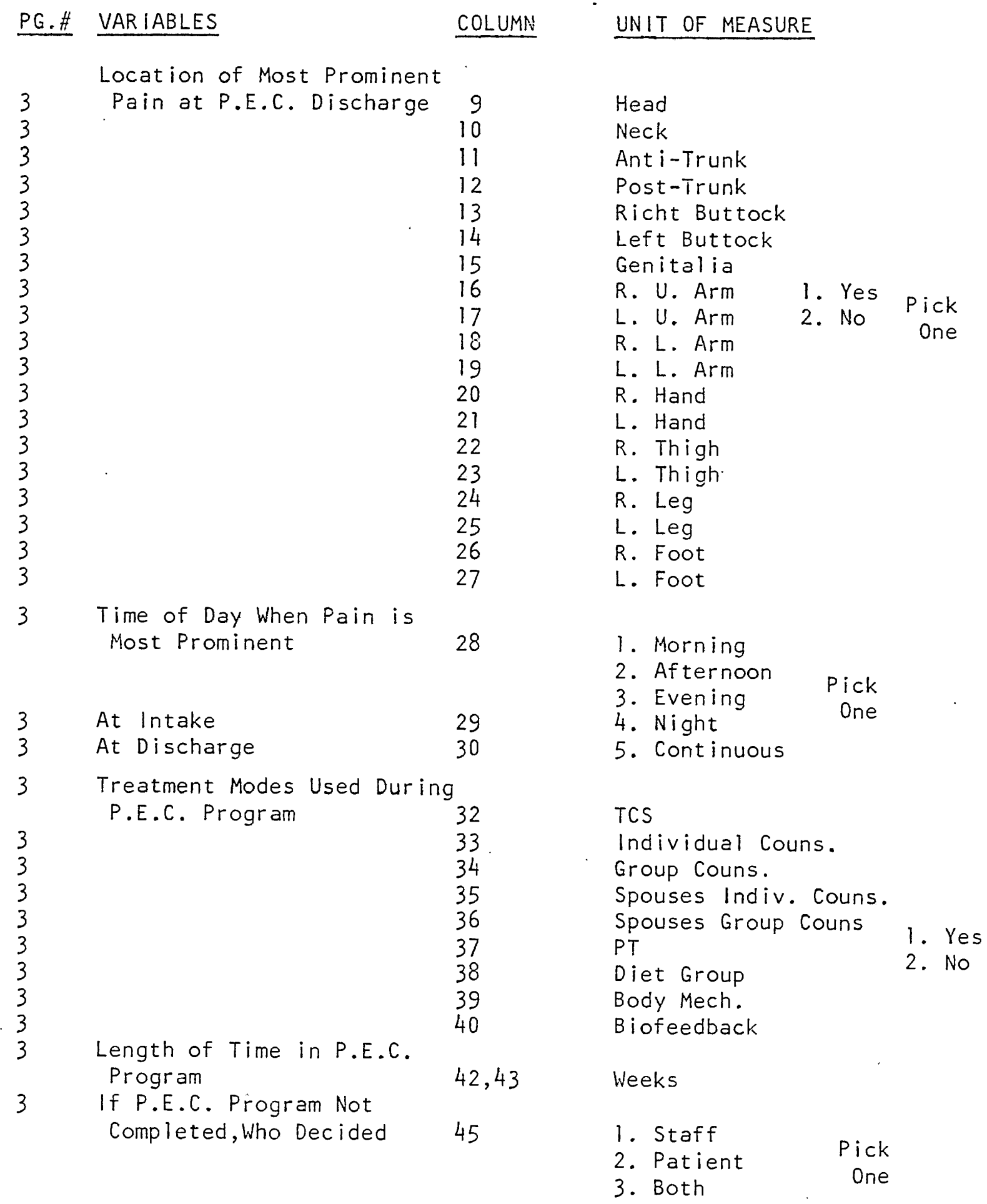




\begin{tabular}{|c|c|c|c|}
\hline$P G . \#$ & VAR IABLES & COLUMN & UNIT OF MEASURE \\
\hline 3 & Ionath of Timo cinco & 46 & \begin{tabular}{l} 
1. Psychologically Unaccepted \\
2. Poor Motivation \\
3. Physically Acute Condition \\
4. Finances \\
5. Transportation Problems \\
6. Moved \\
7. Family Pressure \\
8. Returned to Work Pick \\
9. Went to Different One \\
\multicolumn{2}{c}{ Program }
\end{tabular} \\
\hline 3 & $\begin{array}{l}\text { Length of Time Since } \\
\text { Leaving P.E.C. Program } \\
\text { Date First Seen in } \\
\text { P.E.C. Program }\end{array}$ & $\begin{array}{l}48,49 \\
51,52,53 \\
54,55,56\end{array}$ & $\begin{array}{l}\text { Months } \\
\text { Date }\end{array}$ \\
\hline $\begin{array}{l}3 \\
3\end{array}$ & $\begin{array}{l}\text { Counselor } \\
\text { Start } \\
\text { Finish }\end{array}$ & $\begin{array}{l}58 \\
59\end{array}$ & $\begin{array}{l}\text { 1. Al ison } \\
\text { 2. Ken } \\
\text { 3. Carl }\end{array}$ \\
\hline 3 & $\begin{array}{l}\text { Surgeries Related to } \\
\text { Pain Cundition }\end{array}$ & 61,62 & No. of Surgeries \\
\hline
\end{tabular}




\begin{tabular}{|c|c|c|c|}
\hline$P G . \#$ & VARIABLES & COLUMN & UNIT OF MEASURE \\
\hline 4 & Intake Staffing & $\begin{array}{r}10,11,12 \\
13,14,15\end{array}$ & Date of Intake \\
\hline 4 & Phase I Staffing & $\begin{array}{l}17,18,19 \\
20,21,22\end{array}$ & Date of Phase I Staffing \\
\hline 4 & Treatment Modes Used & $\begin{array}{l}\text { Listed } \\
\text { Straight } \\
\text { Down } \\
\text { On } \\
\text { Demo- } \\
\text { graphic }\end{array}$ & $\begin{array}{l}\text { 1. Evaluation Counseling } \\
\text { 2. Nurses Consultation } \\
\text { 3. Individual Counseling } \\
\text { 4. Group Counseling } \\
\text { 5. Spouses Indiv. Counseling } \\
\text { 6. Spouses Group Counseling } \\
\text { 7. Physical Therapy } \\
\text { 8. Diet Group } \\
\text { 9. Body Mechanics } \\
\text { 10. TENS } \\
\text { 11. Biofeedback } \\
\text { 12. Telephone }\end{array}$ \\
\hline 4 & How Many Modes Used & 27,28 & No. of Sessions Per Mode \\
\hline 4 & $\begin{array}{l}\text { Dates } \\
\text { MILEAGE }\end{array}$ & 30 thru 77 & Dates Seen Per Mode \\
\hline $\begin{array}{l}5 \\
5 \\
5 \\
5\end{array}$ & $\begin{array}{l}\text { Patient No. } \\
\text { Field No. } \\
\text { Page No. } \\
\text { Mileage }\end{array}$ & $\begin{array}{l}1,2,3 \\
4,5 \\
6,7 \\
9,10,11\end{array}$ & $\begin{array}{l}\text { No. of Miles to Pain Clinic } \\
\text { From Patient's Home }\end{array}$ \\
\hline
\end{tabular}


M. M. P. 1.

FIELD NO. 02

PG.\# VARIABLES

Patient's File No.

Field No.

1. Pre 2. Post

MMPI Profile \& Summary

?

L

$\mathrm{F}$

$\mathrm{K}$

HS

D

HY

PD

MF

$P A$

PT

SC

MA

SI

RS

SD

$O D$

S.H.Y.

O.H.Y.

S.P.D.

O.P.D.

S.P.A.

O.P.A.

S.M.A.

O.M.A.

Rotter IE
COLUMN UNIT OF MEASURE

$1,2,3$

$4,5,6,7$

9

10,11

12,13

14,15

16,17

18,19

20,21

22,23

24,25

26,27

28,29

30,31

32,33

34,35

36,37

38,39

40,41

42,43

44,45

46,47

48,49

50,51

$52 ; 53$

54,55

56,57

58,59

62,63
?

L

$\mathrm{F}$

K

HS

D

HY

PD

MF

PA

PT

$S C$

$M A$

SI

Count of Spaces on Testing SD

$O D$

S.H.Y.

O.H.Y.

S.P.D.

O.P.D.

S.P.A.

O.P.A.

S.M.A.

$0 . M . Q$.

Score of Rotter 
MCGILLS

FIELD NO. 03

\section{PG.\# VARIABLES}

Patient File No.

Field No.

Page No.

Date

Words That Describe Pain

Present Pain Index

\section{PRI}

$S$

A

E

$M$

VA

Words
COLUMN

UNIT OF MEASURE

$1,2,3$

4,5

6,7

$9,10,11,12$

13,14 First McGill (Pre)

16

17,18

19,20

21,22

23

24,25

26,27

28,29
1. Mild

2. Discomforting

3. Distressing

4. Horrible

5. Excruciating

Pain Rating Index

Sensory

Affective

Evaluative

Miscell laneous

Visual Analogue

No. of Words Chosen

Repeat for each MCGill (Pre and Post) for as many dates as there are McGills. 
DAILY LOGS

FIELD NO. 04

PG.\# VARIABLES

COLUMN UNIT OF MEASURE

Patient File No.

Field No.

Page No.

Date

Pain Intensity

Up Time

Down Time

Sitting Time

Sleep Time

Drug Time

$1,2,3$

4,5

6,7

$10,11,12$

$13,14,15$

$17,18,19$

Hours Per Day

$22,23,24$ Hours Per Day

$27,28,29$ Hours Per Day

$32,33,34$ Hours Per Day

$37,38,39$ Hours Per Day

$41,42,43$, 44,45

Category Identification

1. Prescription Drug

2. Non-Prescription Drug

1. Analgesic

2. Tranquilizer

3. Mood Elevator

4. Anti-Inf lammatory

5. Hormones

6. Diuretic or Anti-Hypertens

7. Heart Medication

8. Sleeping Pill Sedative

9. Miscellaneous

(Non-Contributory) Drug

Identification by Name 00!-180

Cont. On Next Page

1 Average Daily Intake

Repeat For Each Dr

Repeat For Each Drug

1 Drug Code

Avèrage Daily Intake

$51,52,53,54,55$

$57,58,59$ 


\section{DIAGNOSIS \& SYMPTOMS}

FIELD NO. 05

\begin{tabular}{llll} 
PG.\# & VARIABLES & COLUMN & UNIT OF MEASURE \\
\cline { 2 - 3 } & Patient File No. & $1,2,3$ & \\
1 & Field No. & 4,5 & \\
1 & Page No. & 6,7 & \\
1 & Diagnosis & 9 Thru 30 & Diagnosis \\
1 & Symptoms & 31 Thru 80 Symptoms \\
2 & Surgeries & 9 Thru 45 & Surgeries \\
2 & Diagnostic & 46 Thru 80 diagnostic \\
3 & Drugs & 9 Thru 80 & Druge
\end{tabular}

Categories for Symptoms, Diagnosis, Surgeries, Diagnostics are on the following pages. 


\section{SYMPTOMS}

\section{RESPIRATORY SYSTEM \& LYMPHATICS}

775.6 Edema

775.7 Swollen Glands

776.1 Nosebleed

778.2 Difficulty Breathing

778.4 Rales

778.6 Wheezing

779.3 Cough

786.8 Sub-Q Emphysema

792.5 Allergy

\section{DIGESTIVE SYSTEM}

791.0 Abnromal Weight Gain

781.0 Anorexia (loss of appetite)

$781.1 \quad$ Nausea

$781.2 \quad$ Vomiting

781.7 Heartburn

$782.0 \quad$ G.l.Bleeding

782.1 Diarrhea

791.1 Abnormal Weight Loss

791.3 Increased Appetite

\section{UR INARY SYSTEM}

$\begin{array}{ll}595.9 & \text { Bladder Infections } \\ 783.9 & \text { Urinary Problems } \\ 784.7 & \text { Impotence }\end{array}$

SKIN

$786.2 \quad$ Itching

786.8 Sub-Q Emphysema

\section{HEART \& VESSELS}

774.0 'Chest Pain - Angina

774.2 Tachycardia (rapid heart rate 120)

774.3 Bradycardia (slow heart rate 60 )

774.5 Heart Murmur

401.0 Hypertension

458.0 Hypotension

774.8 Miscellaneous (irregularity, etc.)

$788.8 \quad$ clubbing of fingers 


\section{DIAGNOSIS}

304.0 305.4 306.0 308.8 309.2

311.5

311.7

313.0

314.0

385.0

805.0

357.2

357.9

357.9

053.9

355.9

355.9

320.0

715.0

401.0

713.0

712.9

357.0

250.0

345.9

829.0

839.0

840.9

850.0

860.0

910.0

792.0

789.0

789.1

346.0

997.2

756.3

713.1

848.9

239.9

269.2

721.9

310.0

277.0
Organic Brain Syndrome

Epilepsy

Schizophrenia

Manic-Depressive

Paranoid States

Hysterical Personality

Sociopath

Alcohol ism

Drug Dependence

Menieres Disease

Fractured Vertebral Column

Carpal Tunnel

Diabetic Neuropathy

Peripheral Neuropathy

Post-Herpetic Neuralgia

Neuralgia

Neuritis

Arachnoiditis

Arthritis

Hypertension

Degenerative Arthritis

Rheumatoid Arthritis

Thoratic Outlet Syndrome ( $c-r i b)$

Diabetes

Epilepsy

Bone Fractures

Bone Dislocations

Muscle Injuries (spring, strain, etc.)

Intracranial (head) Injury

Injuries to Chest, Abdomen or Pelvis

Superficial Injuries (abrasions, etc.)

Headaches

Neck Pain

Back Pain

Migraine Headaches

Phantom Limb Pain

Spondylosis

Spondylitis

Sprain or Strain

Cancer

Mal absorption

Pseudoarthrosis

Anxiety

Obesity 
MISCELLANEOUS

$792.7 \quad$ Fatigue

792.6 Nervousness

792.8 Depression

791.2 Thirst

789.7 Abnormal Posture

NERVOUS SYSTEM

770.0 . Coma

250.1 Diabetic Coma

770.1 Drowsiness - Stupor

770.3 Convulsions

770.4 Vertigo - Dizziness

770.7 Memory Disturbance

770.9 Encephalopathy

771.3 Blurred Vision

771.4 Hemianopsia

771.5 Other Visual Disturbance

$771.6 \quad$ Photophobia

771.7 Hystagmus-diploplia

772.4 Tinnitus (ringing in ears)

772.6 Paresthesia (tingling, burning)

772.7 Numbness (hypesthesia)

772.8 Loss of Smell - Taste

773.3 Abnormal Reflex

773.2 Abnormal Involuntary Movement

773.4 Disturbance of Coordination

773.6 Sleep Disturbance

773.7 Cranial Nerve Abnormalities

$777.8 \quad$ Choking

781.4 Dysphagia (difficulty swallowing)

773.6 Dysphasia (difficulty with speech)

792.0 Headache

789.8 Weakness

773.2 Tremor 
DIAGNOSTIC STUDIES

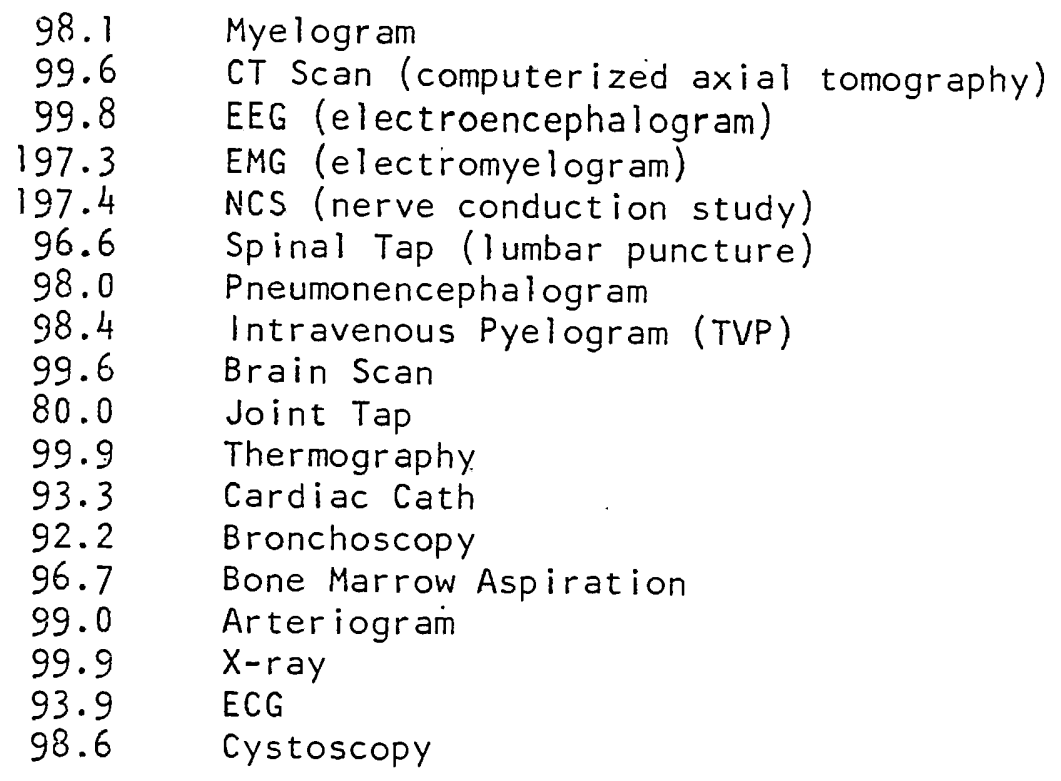

THERAPY

$\begin{array}{ll}95.6 & \text { Traction } \\ 97.6 & \text { Physical Therapy } \\ 97.0 & \text { Cobalt Therapy } \\ 97.2 & \text { Chemotherapy } \\ 97.3 & \text { Electrotherapy } \\ 94.8 & \text { Injection of Nerve } \\ 95.5 & \text { Casting or Brace } \\ 97.5 & \text { Psychotherapy } \\ 97.7 & \text { Occupational Therapy-Speech-Education } \\ 97.8 & \text { Acupuncture } \\ 95.8 & \text { Manipulation-Chiropractic } \\ 97.5 & \text { Hypnosis }\end{array}$


PAIN (Cont)

789.2

789.0

789.1

789.3

789.4

792.1

792.0

997.2

Chest Wall Pain

Neck Pain

Back Pain

Muscle Pain

Muscle Cramp or Spasm

Generalized Pain

Headaches

Phantom Limb Pain

SURGERIES..Related

$\begin{aligned} 03.1 & \text { Rhizotomy } \\ 03.2 & \text { Cordotomy } \\ 05.1 & \text { Sympathectomy } \\ 81.0 & \text { Fusion } \\ 03.0 & \text { Laminectomy } \\ 04.0 & \text { Carpal Tunnel } \\ 83.8 & \text { Tendom Surgery } \\ 80.7 & \text { Menisectomy } \\ 69.6 & \text { Ligament Repair } \\ 81.5 & \text { Total Hip Replacement } \\ 81.9 & \text { Arthroplasty } \\ 79.0 & \text { Bone Fracture } \\ 82.1 & \text { Dupuytrens Contracture } \\ 78.5 & \text { Patellectomy } \\ 03.4 & \text { Spina Bifeda } \\ 81.4 & \text { Total Knee } \\ 39.5 & \text { Aneurysm } \\ 04.1 & \text { Peripheral Nerve Operation } \\ 82.2 & \text { Muscle Surgery } \\ 897.0 & \text { Amputation-Leg } \\ 887.0 & \text { Amputation-Arm } \\ 01.1 & \text { Craniotomy }\end{aligned}$

SURGERIES. . Non-Related

$\begin{array}{ll}35.2 & \text { Heart Graft } \\ 38.4 & \text { Vein Stripping } \\ 46.5 & \text { Colostomy } \\ 06.2 & \text { Throidectomy } \\ 37.8 & \text { Pacemaker } \\ 51.9 & \text { Gallbladder } \\ 55.5 & \text { Ulcer Surgery } \\ 40.3 & \text { Radical Neck } \\ 53.0 & \text { Hernia } \\ 59.7 & \text { Hysterectomy } \\ 60.2 & \text { Prostatectomy }\end{array}$


SURGERIES. . Non-Related

$\begin{array}{ll}20.9 & \text { Mastoidectomy } \\ 15.3 & \text { Cataract } \\ 18.0 & \text { Ear Operations } \\ 21.0 & \text { Nose Operations } \\ 23.7 & \text { Root Canal } \\ 27.0 & \text { Facial Operations } \\ 30.0 & \text { Operations on Respiratory System } \\ 35.0 & \text { Operations on Cardiovascular System } \\ 40.0 & \text { Operations on Blood and Lymphatic Systems } \\ 42.0 & \text { Operations on Digestive System } \\ 55.0 & \text { Operations on Urinary System } \\ 60.0 & \text { Operations on Male Genital System } \\ 65.0 & \text { Operations on Female Genital System } \\ 86.0 & \text { Mastectomy } \\ 88.0 & \text { Operations on Skin } \\ 39.3 & \text { Hemmorhoidectomy }\end{array}$




\begin{tabular}{|c|c|c|c|}
\hline APC & 00121 & DILANTIN & 04512 \\
\hline ACETAMINOPHEN & 00221 & DILAUDID & 04611 \\
\hline ACT IFED & 00319 & DIVIL & 04811 \\
\hline ALDACTAZ IDE & 00416 & DOLSPHINE & 04919 \\
\hline ALDOMET & 00516 & DONNATAL & 05018 \\
\hline APRESSL INE & 00616 & DOR IDEN & 05118 \\
\hline \multirow[t]{3}{*}{$A S P I R I N$} & 00721 & DOXIDAN & 05118 \\
\hline & & DRAMAMINE & 05222 \\
\hline & & DRIXORAL & 05319 \\
\hline BELAP & 00819 & DULCOLAX & 05429 \\
\hline BENADRYL & 00919 & DYAZ IDE & 05516 \\
\hline BENEMID & 01019 & DYSPAS & 05619 \\
\hline BETA CHLOR & 01118 & & \\
\hline BUFFERIN & 01221 & & \\
\hline BUTABARB IOL & 01318 & ECOTR IN & 05721 \\
\hline \multirow[t]{3}{*}{ BUTAZOLID IN } & 01414 & ELAVIL & 05813 \\
\hline & & EMPIR IN & 05921 \\
\hline & & EQUAN IL & 06012 \\
\hline CAFERGOT & 01511 & ERGOSTAT & 06115 \\
\hline CARD ILATE & 01617 & ESIDRIX & 06216 \\
\hline CATAPRES & 01716 & ESKATROL & 06313 \\
\hline CHLORAL HYDRATE & 01818 & EUTHRO ID & 06415 \\
\hline CHLORANPHEN ICOL & 01919 & EXEDR IN & 06521 \\
\hline CHLORPROMAZINE & 02012 & & \\
\hline CHYMORAL & 02119 & & \\
\hline CODE INE SULFATE & 00221 & FIOR INAL & 06611 \\
\hline COLBENEMID & 02319 & & \\
\hline COLCHICINE & 02419 & & \\
\hline COMB ID & 02512 & GELUSIL & 06729 \\
\hline CORCIDIN & 02629 & & \\
\hline CORTISONE & 02714 & & \\
\hline COTAZYME & 02819 & HYDROCHLOROTHIAZIDE & 06216 \\
\hline \multirow[t]{3}{*}{ CYSTOSPAS } & 02919 & HYDRODIURIL. & 06216 \\
\hline & & HYDROPRES & 06816 \\
\hline & & HYGROTON & 06916 \\
\hline$B \mid T-T D$ & 03015 & & \\
\hline DALMANE & 03118 & & \\
\hline DANTRUIM & 03212 & IMURAN & 0701 \\
\hline DARVOCET $N$ & 03311 & INDERAL & 0711 \\
\hline DARVON & 03411 & INDOAIN & 0721 \\
\hline DARVON 65 & 03511 & INSULIN & 07315 \\
\hline DARVON N & 93611 & ISMEL IN & 07417 \\
\hline DECADRON & 03714 & ISORDIN & 07517 \\
\hline DEMEROL & 03811 & ISUPREL & 0761 \\
\hline DEPO-MEDROL & 03914 & & \\
\hline DEXEDR INE & 04013 & LANOXIN & 07717 \\
\hline$D I A B$ INESE & 04115 & LASIX & 07816 \\
\hline DIALOS & 04229 & LEVO DROMERAN & 0791 \\
\hline DIAMOX & 04319 & LEVOPHEN & 08017 \\
\hline \multirow[t]{3}{*}{ DIGOXIN } & 04417 & LEBRAX & 08112 \\
\hline & & LIBR IUM & 08212 \\
\hline & & LOMOTIL & 0831 \\
\hline
\end{tabular}


LORFAN

LOR ID INE

MELLARIL

MAALOX

MEPRODOMATE

METHADONE

MILTOWN

MINIPRES

MOTRIN

MYLANTA

MYLICON

MYSOL INE

MORPHINE

NALFON

NARCON

NARD IL

NEMBUTAL

NEOSYNEPHR INE

NICOBID

NISENTIL

NOLUDAR

NORFLEX

NORGESIC

NUMORPHAN

OR INASE

PAPAVER INE

PARAFON FORTE

PAVABID

PERCODAN

PERCOGESIC

PER IACTIN

PER ITRATE

PHENAPHEN

PHENERGAN

PHENOBARB ITAL

PLACIDYL

PREDNISONE

PREMAR IN

PROBANTHINE

PROL IXION

PROMETHAZ INE

PRONESTYL

PROPOXYPHENE
08511

08611

087.13

08829

06012

08911

06012

09016

09114

09229

09329

09412

09511

09611

09711

09811

09918

10017

10119

10217

10318

10412

10512

10611

10715

10819

10911

11019

11111

11211

11319

11417

11511

11612

11718

11818

11914

12015

12119

12213

12312

12417

03611
QUAALUDE

QUINIDINE

12518

12617

RESERPINE

12716

RISPAN

12829

RITALIN

12913

ROBAXIN

13012

SANSERT

13119

SECONAL

SER AP ES

13218

13312

SERAX

13412

SERPAS IL

13517

SINEQUAN

SOMA

13613

13712

SORB ITRATE

13817

STRESSTAB

SUDAFED

SYNALAR

SYNTHROID

SPAR INE

STELAZ INE

13912

14029

14111

14215

14312

14412

TALQIN

TEDRAL

TEGRETOL

TELDR IN

TEMARIL

TENSILON

THORAZIRCE

THYROID

TIGAN

TITR ILAC

TOFRAN IL

TR ILAFON

TYLENOL

1.4511

14619

14712

14819

14919

15017

15112

15215

15312

15429

15513

15612

15713

VAL IUM

15912

VASODILAN

VISTAR IL

16017

16112

VAVACTIL

16213

ZACTR IN

1631.3

ZYEOPRIN 
DESIRED CHANGE

FIELD NO. 07

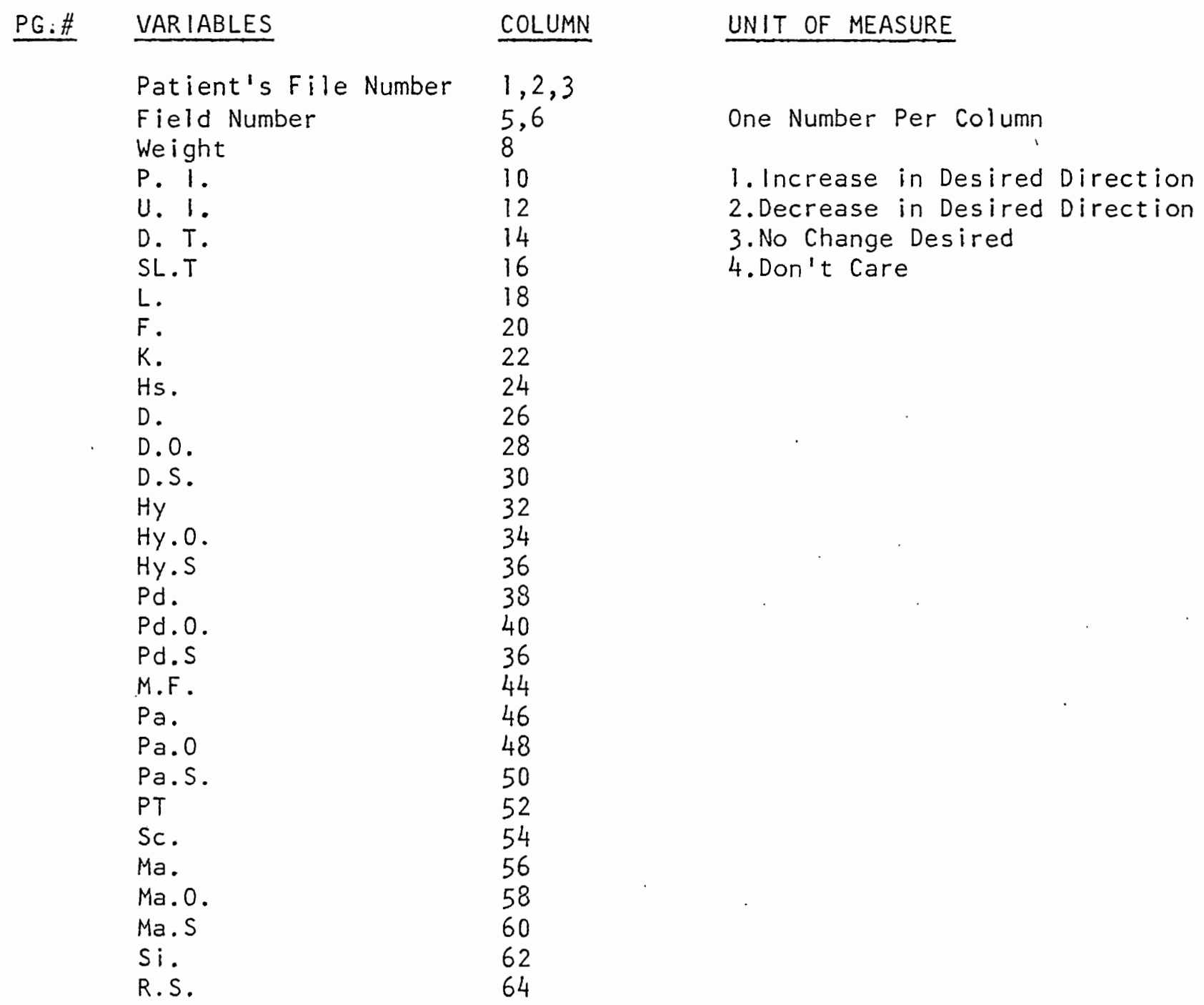


STIMULATOR TIMES

FIELD NO. 0.8

\section{PG:\# VARIABLES}

1 Patient's File No.

Field No.

Date

Stimulator

Date

Stimulator

Date

Stimulator

Date

Stimulator

Date

Stimulator

Date

Stimulator

Date

St imulator
COLUMN

$1,2,3$

4,5

6 thru 11

12 thru 14

$16-21$

$22-24$

$26-31$

$32-34$

$36-41$

$42-44$

46-51

$52-54$

$56-61$

$62-64$

$66-71$

$72-74$
UNIT OF MEASURE

First Day of Week

Hours in a Week

Hours in a Week

Hours in a Week

Hours in a Week

Hours in a Week

Hours in a Week Hours in a Week

Hours in a Week

Hours in a Week

Hours in a Week Hours in a Week

Hours in a Week Hours in a Week 
RO-COMS

FIELD NO. O9

PG.\# VARIABLES

COLUMN

UNIT OF MEASURE

Patient File No.

$1,2,3$

Field No.

4,5

Page No.

6,7

No. of "Yes" Answers

$9,10,11$

Patient's File No.

$14,15,16$

Field No.

14,18

Page No.

19,20

No. of "Yes" Answers 22,23,24 


\author{
$F$ AND HS SCALE \\ PRE M.M.P.1. (Uses same) \\ FIELD NO. $14 \& 15$
}

\begin{tabular}{|c|c|c|c|c|}
\hline$P G$.\# & VAR IABLES & COLUMN & \multicolumn{2}{|c|}{ UNIT OF MEASURE } \\
\hline & Questions & & 1-True & $0-F a l s e$ \\
\hline 1 & 14 & 9 & & \\
\hline 1 & 17 & 10 & & \\
\hline 1 & 20 & 11 & & \\
\hline 1 & 27 & 12 & & \\
\hline 1 & 31 & 13 & & \\
\hline 1 & 34 & 14 & & \\
\hline 1 & 35 & 15 & & \\
\hline 1 & 40 & 16 & & \\
\hline 1 & 48 & 17 & & \\
\hline 1 & 49 & 18 & & \\
\hline 1 & 50 & 19 & & \\
\hline 1 & 53 & 20 & & \\
\hline 1 & 54 & 21 & & \\
\hline 1 & 56 & 22 & & \\
\hline 1 & 65 & 23 & & \\
\hline 1 & 66 & 24 & & \\
\hline 1 & 75 & 25 & & \\
\hline 1 & 83 & 26 & & \\
\hline 1 & 85 & 27 & & \\
\hline 1 & 112 & 28 & & \\
\hline 1 & 113 & 29 & & \\
\hline 1 & 115 & 30 & & \\
\hline 1 & 121 & 31 & & \\
\hline 1 & 123 & 32 & & \\
\hline 1 & 139 & 33 & & \\
\hline 1 & 146 & 34 & & \\
\hline 1 & 151 & 35 & & \\
\hline 1 & 156 & 36 & & \\
\hline 1 & 164 & 37 & & \\
\hline 1 & 168 & 39 & & \\
\hline 1. & 169 & 40 & & \\
\hline 1 & 177 & 41 & & \\
\hline 1 & 184 & 42 & & \\
\hline 1 & 185 & 43 & & \\
\hline 1 & 196 & 44 & & \\
\hline 1 & 197 & 45 & & \\
\hline 1 & 199 & 46 & & \\
\hline 1 & 200 & 47 & & \\
\hline 1 & 202 & 48 & & \\
\hline
\end{tabular}


F AND HS SCALE (cont)

\begin{tabular}{llll} 
PG.\# & VARIABLES & COLUMN & UNIT OF MEASURE \\
\cline { 2 - 3 } 1 & 205 & 49 & \\
1 & 206 & 50 & \\
1 & 209 & 51 & \\
1 & 210 & 52 & \\
1 & 245 & 53 \\
1 & 246 & 54 \\
1 & 247 & 55 \\
1 & 252 & 56 & \\
1 & 256 & 57 & \\
1 & 257 & 58 \\
1 & 258 & 59
\end{tabular}


HS SCALE

(Same Scaling for: Pre M.M.P.1. 14)

Post M.M.P.I. 15)

PG.\# VARIABLES

COLUMN

UNIT OF MEASURE

Questions on Hs Scale

$\begin{array}{lll}1 & 2 & 68 \\ 1 & 3 & 69 \\ 1 & 7 & 70 \\ 1 & 9 & 71 \\ 1 & 18 & 72 \\ 1 & 23 & 73 \\ 1 & 29 & 74 \\ 1 & 43 & 75 \\ 1 & 51 & 76 \\ 1 & 55 & 77 \\ 1 & 2 & 78 \\ 1 & 63 & 79 \\ 1 & 68 & 80 \\ 1 & 72 & 9 \\ 1 & 103 & 10 \\ 1 & 108 & 11 \\ 1 & 114 & 12 \\ 1 & 125 & 13 \\ 1 & 130 & 14 \\ 1 & 153 & 15 \\ 1 & 155 & 16 \\ 1 & 161 & 17 \\ 1 & 163 & 18 \\ 1 & 175 & 19 \\ 1 & 188 & 20 \\ 1 & 189 & 21 \\ 1 & 190 & 22 \\ 1 & 192 & 23 \\ 1 & 230 & 24 \\ 1 & 243 & 25 \\ 1 & 273 & 26 \\ 1 & 274 & 27 \\ 1 & 281 & 28\end{array}$


HS SCALE

Pre M.M.P.I. (Uses Same)

Post M.M.P.1. (Scale E Columns)

FIELD NO. $14 \& 15$

\section{PG.\# VARIABLES}

272

275

276

286

288

291

293
COLUMN

61

62

63

64

65

66

67
UNIT OF MEASURE

1-True 2-False 
M.M.P.I. 'D' SCALE

PRE AND POST USE THE SAME SCALING

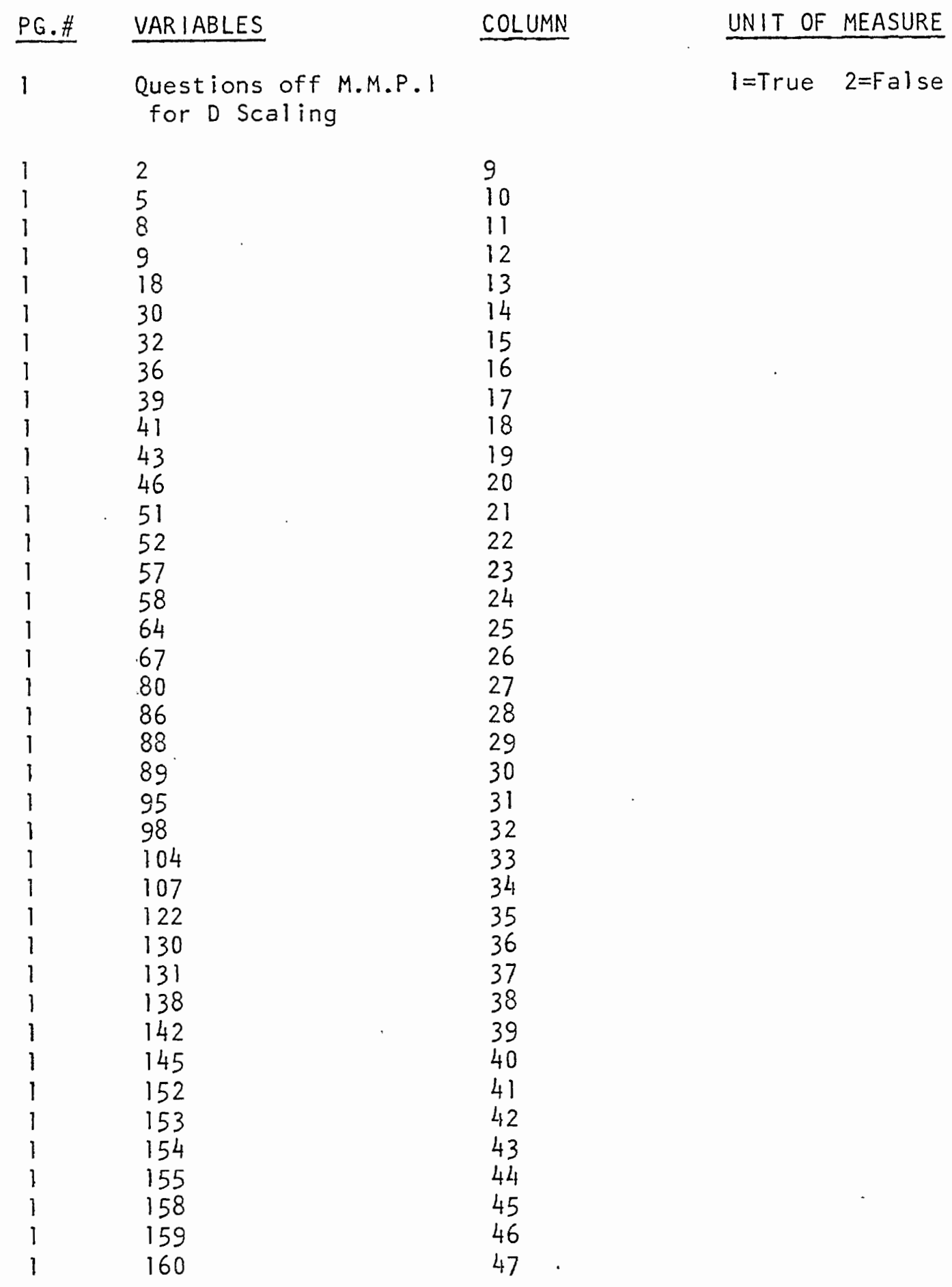


M.M.P.I. 'D' SCALE (cont)

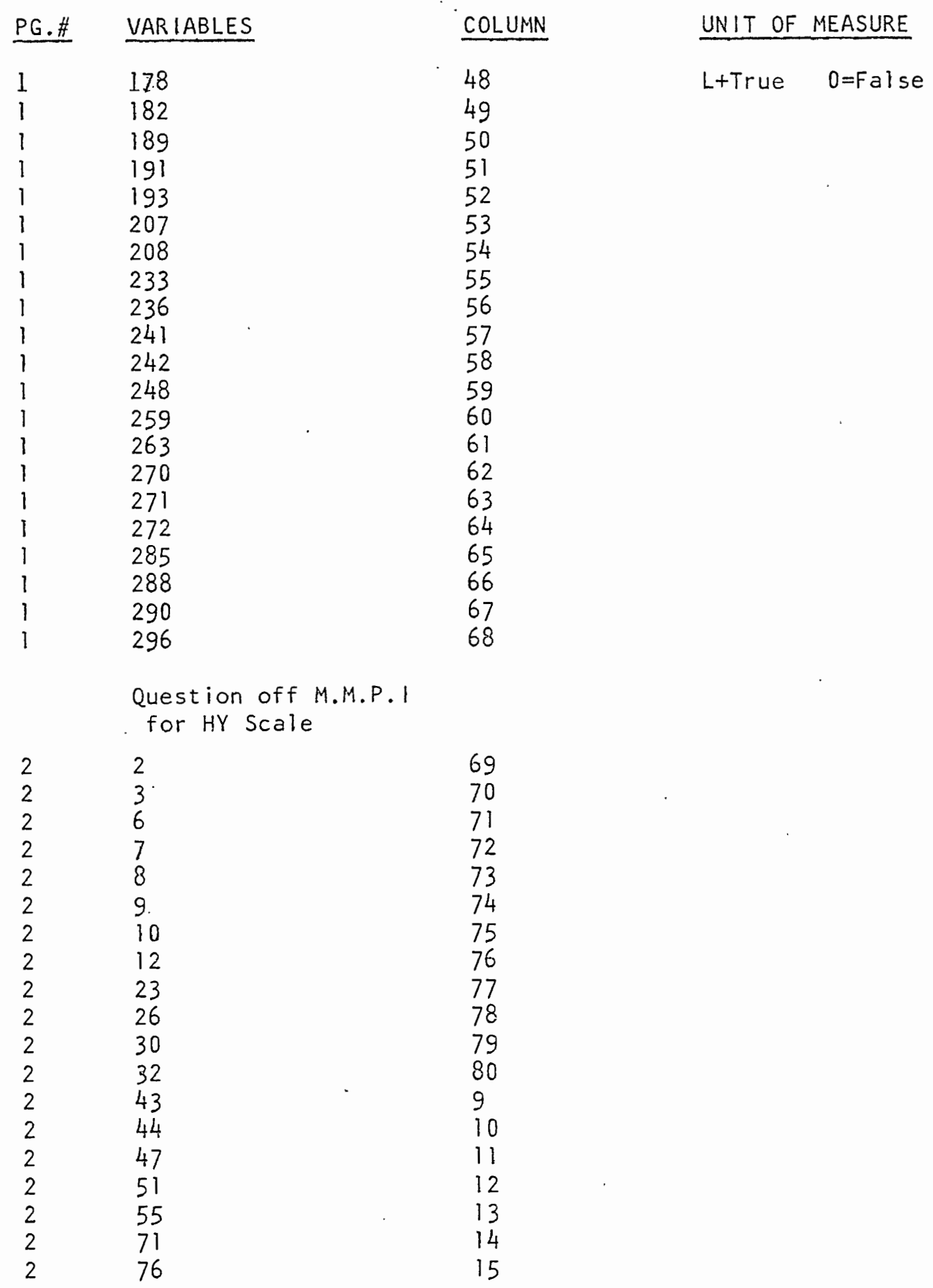


M.M.P.I. HY SCALE (Cont)

\begin{tabular}{|c|c|c|c|}
\hline PG.\# & VARIABLES & COLUMN & UNIT OF MEASURE \\
\hline 2 & 89 & 16 & $0=\mathrm{False}$ \\
\hline 2 & & 17 & \\
\hline 2 & 103 & 18 & \\
\hline 2 & 107 & 19 & \\
\hline 2 & 109 & 20 & \\
\hline 2 & 114 & 21 & \\
\hline 2 & 124 & 22 & \\
\hline 2 & 128 & 23 & \\
\hline 2 & 129 & 24 & \\
\hline 2 & 136 & 25 & \\
\hline 2 & 137 & 26 & \\
\hline 2 & 141 & 27 & \\
\hline 2 & 147 & 28 & \\
\hline 2 & 153 & 29 & \\
\hline 2 & 160 & 30 & \\
\hline 2 & 162 & 31 & \\
\hline 2 & 163 & 32 & \\
\hline 2 & 170 & 33 & \\
\hline 2 & 172 & 34 & \\
\hline 2 & 174 & 35 & \\
\hline 2 & 175 & 36 & \\
\hline 2 & 179 & 37 & \\
\hline 2 & 180 & 38 & \\
\hline 2 & 186 & 39 & \\
\hline 2 & 188 & 40 & \\
\hline 2 & 189 & 41 & \\
\hline 2 & 190 & 42 & \\
\hline 2 & 192 & 43 & \\
\hline 2 & 201 & 44 & \\
\hline 2 & 213 & 45 & \\
\hline 2 & 230 & 46 & \\
\hline 2 & 234 & 47 & \\
\hline 2 & 238 & 48 & \\
\hline 2 & 243 & 49 & \\
\hline 2 & 253 & 50 & \\
\hline 2 & 265 & 51 & \\
\hline 2 & 267 & 52 & \\
\hline 2 & 274 & 53 & \\
\hline 2 & 279 & 54 & \\
\hline 2 & 289 & 55 & \\
\hline 2 & 292 & 56 & \\
\hline
\end{tabular}

